\title{
A Cost-Benefit Analysis of Capacitor Allocation Problem in Radial Distribution Networks Using an Improved Stochastic Fractal Search Algorithm
}

\author{
Phuoc Tri Nguyen $\mathbb{D}^{1},{ }^{1}$ Thi Nguyen Anh $\mathbb{D}^{1},{ }^{1}$ Dieu Vo Ngoc $\mathbb{D}^{1},{ }^{1,2}$ and Tung Le Thanh ${ }^{3}$ \\ ${ }^{1}$ Department of Power Systems, Ho Chi Minh City University of Technology (HCMUT), 268 Ly Thuong Kiet Street, District 10, \\ Ho Chi Minh, Vietnam \\ ${ }^{2}$ Vietnam National University Ho Chi Minh City, Linh Trung Ward, Thu Duc District, Ho Chi Minh, Vietnam \\ ${ }^{3}$ Department of Electrical and Electronic Engineering, Faculty of Engineering and Technology, Tra Vinh University, \\ 126 Nguyen Thien Thanh Street, Tra Vinh, Vietnam \\ Correspondence should be addressed to Dieu Vo Ngoc; vndieu@hcmut.edu.vn
}

Received 17 August 2020; Revised 9 November 2020; Accepted 17 November 2020; Published 1 December 2020

Academic Editor: Honglei Xu

Copyright $\odot 2020$ Phuoc Tri Nguyen et al. This is an open access article distributed under the Creative Commons Attribution License, which permits unrestricted use, distribution, and reproduction in any medium, provided the original work is properly cited.

\begin{abstract}
This research proposes a modified metaheuristic optimization algorithm, named as improved stochastic fractal search (ISFS), which is formed based on the integration of the quasiopposition-based learning (QOBL) and chaotic local search (CLS) schemes into the original SFS algorithm for solving the optimal capacitor placement (OCP) in radial distribution networks (RDNs). The test problem involves the determination of the optimal number, location, and size of fixed and switched capacitors at different loading conditions so that the network total yearly cost is minimized with simultaneous fulfillment of operating constraints. Also, the hourly on/off scheduling plans of switched shunt capacitors (SCs) considering a modified cost objective function are obtained. The proposed ISFS algorithm has been tested on two IEEE 69-bus and 119-bus RDNs and a practical 152-bus RDN. For clarifying the effectiveness and validation of the ISFS, the simulated results have been compared with those of other previously utilized solution approaches in the literature as well as the original SFS. From result comparison, the proposed ISFS outperforms other previous approaches regarding solution quality and statistical performance for the compared cases, especially in the complex and large-scale networks. Notably, compared with the original SFS, the proposed ISFS shows a significantly better performance in all the tested cases.
\end{abstract}

\section{Introduction}

Due to the rapidly increasing load demand, the electrical distribution networks are facing excessive burdens, leading to a reduced voltage at remote load points. More seriously, the voltage drops can occur at the end of the radial distribution feeder. Another noteworthy point is that, on average, about $13 \%$ of the generated total power is wasted under losses at the distribution level [1]. Accordingly, technical solutions to preserve appropriate voltage levels along the feeder as well as to mitigate distribution losses are extremely necessary for improving power delivery efficiency.
Shunt capacitor banks (SCs) have been widely utilized to compensate for reactive power in radial distribution networks (RDNs) with intent to acquire loss reduction, to enhance the feeder voltage profile and overall power factor, and to release available feeder capacity [2]. The employment of SCs helps in reducing the reactive power demand of network which consequently decreases line current and reactive power flow. To achieve the aforementioned benefits, capacitor placement must be carefully calculated in RDNs. Considering this problem, the parameters related to the number, location, rating, and operation scheduling of SCs need to be optimally determined so that the overall costs of 
SCs are minimized while fulfilling all the operational constraints. Notably, when examining an RDN with $m$ buses and $n$ available capacitor ratings, the set of candidate solutions will be $(n+1)^{m}$, and thus evaluating $(n+1)^{m}$ solutions is a challenging task, especially for a large-scale RDN. Consequently, there is always a need to search for effective optimization techniques to cope with the optimal capacitor placement (OCP) problem.

Since, in nature, the OCP is a complex combinatorial optimization problem, a huge number of optimization methods have been proposed to solve it. Based on the literature, optimization methods utilized to cope with the problem can be classified into four main groups including analytical, numerical programming, heuristic, and metaheuristic-based optimization methods [3]. Recently, many researchers have tried to employ metaheuristic-based methods for finding the optimal location and rating of SCs such as particle swarm optimization (PSO) algorithm $[4,5]$; genetic algorithm (GA) [6, 7]; plant growth algorithm (PGA) [1]; firefly algorithm (FFA) [8]; harmony search algorithm (HAS) [9]; tabu search (TS) [10]; evolutionary algorithm (EA) [11]; teaching learning-based optimization (TLBO) [12]; bacterial foraging algorithm (BFA) [13]; gravitational search algorithm (GSA) [14]; artificial bee colony algorithm (ABC) [15]; cuckoo search optimization algorithm (CSA) [16]; ant-colony optimization algorithm (ACO) [17]; flower pollination algorithm (FPA) [18]; improved harmony algorithm (IHA) [19]; Limaçon inspired spider monkey optimization algorithm (LSMO) [20]; spring search algorithm (SSA) [21]; grasshopper optimization algorithm (GOA) [22]; improved variables' inclusion and interchange algorithm (IVII) [23]; crow search algorithm (CRS) [24]; modified Gbest-guided artificial bee colony (MGABC) [25]; and fuzzy heuristic-based methods [26-28]. The common point in metaheuristic-based techniques is the use of stochastic rules to inquire about the search space, and thus they are capable of local minima avoidance. As a result, these techniques can solve the problem more effectively when compared to traditional search methods which require convexity, differentiability, and continuity of the designed problem. However, for complex large-scale instances, metaheuristic-based techniques may reveal some major drawbacks such as not being able to find an optimal solution and suffering from long computational time if they are not modified with an effective searching mechanism.

The integration of SCs into RDNs will accomplish many benefits if the number, location, and rating of SCs are optimally assigned. Previous research attempts in the literature had been made to acquire these benefits by optimal SC allocation for minimizing power losses [7, 9-13, 18, 20]; minimizing total cost $[1,8,10,11,14,16-18,29]$; maximizing annual net saving [26]; and enhancing network voltage stability $[14,28]$. These objectives can be formulated as a single-objective function [7-10, 14, 16, 27, 29, 30] or as a multiobjective framework $[5,6,10-13,17,18,26,28,31]$. As realized from the literature, most relevant studies just considered with a predetermined number of SCs for investigations without proposing a specific strategy for determining the optimal number of SCs. Although the penetration of the number of the assumed capacitors may lead to improved network overall performance as revealed in previous reports, the final outcomes may not be optimum. Taking this into account, we have proposed a newly effective scheme for seeking the optimal number of SCs so that the total annual cost is minimized.

Also, it is worth to mention that most of the previous studies examined the OCP under peak loading condition only without including daily continuous load variations, causing undesirable voltage violation at some network buses, particularly for light load levels. In addition, the occurrence of reverse power flow in some situations may result in increased power losses [16, 32]. Besides, only were a few studies in the literature concerned about the switched SCs for optimal placement and scheduling $[7,16,17,19,25,26,28,30]$, while most previous studies considered the OCP with fixed SCs only $[1,6,10-14,18,20,31]$. Selecting capacitors based on fixed reactive power demand only is not suitable for practical and economic viewpoint for which the continuous variation in load demand leads to network voltage change, resulting in reactive power demand change. The proper installation of fixed and switched SCs helps to encumber unwanted voltage violations and achieve daily network loss minimization.

Another important aspect besides the allocation of SCs is that on/off scheduling scheme of switched SCs according to daily load cycles. However, just a handful of studies in the literature discuss this scheduling scenario [22, 33]. Furthermore, the mentioned research studies solved daily switched SCs on/off scheduling scenarios with the aim of power loss minimization. But in our work, a modified annual cost objective function is introduced for the optimal dispatching schedule of switched SCs considering a practical $24 \mathrm{~h}$ load profile. In order to deal with the aforementioned crucial issues, it is imperative to search for a novel powerful optimization algorithm. Stochastic fractal search (SFS) developed by Salimi [34] behaves as a promising robust algorithm, which is modeled based on the growing phenomena of nature by applying the fractal theory. In comparison with other metaheuristic-based algorithms, its original version provided a better searching performance [34]. Nevertheless, due to the stochastic nature of the metaheuristic-based algorithm including SFS, they suffer from premature convergence and local minima problems. It is well known from the literature that the quasiopposition-based learning (QOBL) can be considered as an effective solution to be integrated into original metaheuristic algorithms with the aim of avoiding the situation of local minima. The outstanding instances are the combination of QOBL with DE [35], HS [36], TLBO [37], GWO [38], SIMBO-Q [39], SOS [40], and antlion optimizer (ALO) [41]. Thanks to the QOBL scheme, the capability of the algorithm is enhanced to probe more promising search regions, leading to a higher possibility to obtain a better outcome. Another effective strategy in addition to the QOBL, namely, chaotic local search (CLS), can be applied to prevent being trapped at local minima. This incorporated strategy helps to locally probe the neighborhood of "current best outcome," which provides 
better exploitation of the search space. Different CLS patterns had been incorporated in ALO [41], DE [42-44], HS [45], PSO [46-48], ABC [49], and TLBO [50].

Motivated by the successful application of previous studies to the mentioned strategies, the current research integrated both QOBL and CLS strategies into the framework of the original SFS with intent to enhance computing performance. This modified version is nominated as an improved SFS (ISFS) method. The ISFS employs QOBL for the purpose of group initialization and generation jumping, whereas CLS deals with the current best group. Pertaining to the efficient and feasibility assessment of the proposed ISFS, we adopted it to the poorlyresearched issues of OCP. Specifically, the proposed ISFS algorithm was applied to determine the optimal number, location, size and on/off scheduling plan of SCs with the purpose of total annual cost minimization according to daily load demand variations in the 69-, 119-, and 152-bus RDNs. We also applied its original counterpart to solve the problem for comparative purposes.

Our current research contains some highlighted contributions as follows:

(1) An improved metaheuristic algorithm (ISFS) is proposed for enhancing the performance and solution quality of the OCP problem.

(2) A modified cost objective function is utilized to deal with switched SCs on/off scheduling scenarios considering a practical $24 \mathrm{~h}$ load profile.

(3) A newly effective framework for determining the optimal quantity of SCs to achieve total annual cost minimization by using the proposed ISFS is represented. More specifically, the outcome by this procedure is the inclusion of the optimum quantity, location and rating of SCs as compared to only optimum location, and rating of SCs from the previously published research studies.

(4) A novel initialization process based on only a few adjustments in the original solution algorithm is applied for treating practical discrete capacitor sizes.

(5) The proposed ISFS contributes to remarkably improve the solution quality of the OCP problem for the tested instances based on the comparison of the obtained best results and the reported best-so-far results in the literature.

The rest of the paper is arranged as follows. Section 2 presents the mathematical models of the OCP problem. The formation of the proposed technique is described in detail in Section 3. Next, Section 4 introduces the implementation of the proposed ISFS to the OCP problem. Numerical results and discussion are reported in Section 5. Finally, the conclusion is disclosed in Section 6.

\section{Mathematical Problem Formulation}

The OCP is a constrained nonlinear optimization problem and mathematically stated as follows:

$$
\begin{array}{cl}
\text { Minimize: } & F(x, u)+\text { Penalties, } \\
\text { subject to: } & g(x, u)=0 \\
& h(x, u)=0
\end{array}
$$

in which $F(x, u)$ denotes the objective function which needs to be minimized (i.e., total annual cost); the term Penalties is to penalize solutions violating constraints; $g(x, u)$ and $h(x, u)$ are, respectively, the set of equality and inequality constraints; $x$ stands for the vector of state variables (i.e., voltage and line power flows); and $u$ represents the vector of control variables (i.e., reactive power of SCs).

\subsection{Objective Function}

(1) Conventional cost function:

$$
\begin{aligned}
\operatorname{COST}= & K_{P} \cdot P_{\text {loss }} \cdot T+D \cdot\left(K_{I} \cdot n_{\mathrm{SC}}+K_{C} \cdot \sum_{i=1}^{n_{\mathrm{SC}}} \mathrm{Q}_{\mathrm{SC}, i}\right) \\
& +K_{o} \cdot n_{\mathrm{SC}} .
\end{aligned}
$$

(2) Modified cost function:

$$
\begin{aligned}
\mathrm{MC}= & K_{P} \cdot \sum_{i=1}^{24} P_{\mathrm{loss}, i} \cdot T_{i}+D \cdot\left(K_{I} \cdot n_{\mathrm{SC}}+K_{C} \cdot \sum_{j=1}^{n_{\mathrm{SC}}} \mathrm{Q}_{\mathrm{SC}, j}\right) \\
& +K_{o} \cdot n_{\mathrm{SC}},
\end{aligned}
$$

where $K_{P}, K_{I}, K_{C}$, and $K_{o}$ are, respectively, the costs for average energy loss per $\mathrm{kWh}$, capacitor installation, capacitor purchase per $\mathrm{kVAr}$, and relevant operation. In this work, these parameters are, respectively, chosen to be $0.06 \$$ / $\mathrm{kWh}, 1000 \$ /$ location, $3 \$ / \mathrm{kVAr}$, and $300 \$ /$ year/location. Also, $T$ and $T_{i}$ are, respectively, the total investigation time within a year ( $T=8760$ hours) and the investigation time in a year of the $i$ th time of a day (hours/year) in which the values of $T_{i}$ are given in Table 1 [51]; $D$ is the factor of depreciation; $n_{\mathrm{SC}}$ is the considered number of capacitors; and $Q_{\mathrm{SC}}, i$ indicates the discrete size of capacitor at the $i$ th bus.

2.2. Power Flow Formulation. The study aims to estimate the optimal location and size of SCs in an RDN so that the total annual cost is minimized. Figure 1 illustrates the single-line diagram of a simple radial distribution feeder. Mathematical equations for computing power flow are defined as follows [52]:

$$
\begin{gathered}
P_{i+1}=P_{i}-P_{D i+1}-R_{i, i+1} \cdot \frac{P_{i}^{2}+Q_{i}^{2}}{\left|V_{i}\right|^{2}}, \\
Q_{i+1}=Q_{i}-Q_{D i+1}-X_{i, i+1} \cdot \frac{P_{i}^{2}+Q_{i}^{2}}{\left|V_{i}\right|^{2}},
\end{gathered}
$$


TABLe 1: Average hourly daily load demand [51].

\begin{tabular}{lcc}
\hline Time (hours) & Load level (p.u.) & Hours (year) \\
\hline 1,7 & 0.64 & 730 \\
2 & 0.6 & 365 \\
3,6 & 0.58 & 730 \\
4,5 & 0.56 & 730 \\
8 & 0.76 & 365 \\
9,23 & 0.87 & 730 \\
10 & 0.95 & 365 \\
11,13 & 0.99 & 730 \\
$12,14,15$ & 1 & 1095 \\
16 & 0.97 & 365 \\
17,18 & 0.96 & 730 \\
19,22 & 0.93 & 730 \\
20,21 & 0.92 & 730 \\
24 & 0.72 & 365
\end{tabular}

$$
\begin{aligned}
\left|V_{i+1}\right|^{2}= & \left|V_{i}\right|^{2}-2 \cdot\left(R_{i, i+1} \cdot P_{i}+X_{i, i+1} \cdot Q_{i}\right) \\
& +\left(R_{i, i+1}^{2}+X_{i, i+1}^{2}\right) \cdot \frac{P_{i}^{2}+Q_{i}^{2}}{\left|V_{i}\right|^{2}}
\end{aligned}
$$

where $P_{i}$ and $Q_{i}$ are, respectively, the active and reactive power flowing out of bus $i ; P_{D i+1}$ and $Q_{D i+1}$ are the active and reactive power demands at bus $i+1$, respectively; $R_{i, i+1}$ and $X_{i, i+1}$ are the resistance and reactance of the distribution line section connected between bus $i$ and bus $i+1$; and $\left|V_{i}\right|$ is voltage magnitude of bus $i$. If the active and reactive power balance equations in equations (4) and (5) are fulfilled, the convergence of power flow will occur. Also, voltage magnitudes at sending and receiving end buses must fulfill equation (6). Newton-Raphson iterative algorithm embedded in Matpower software tool [53] was applied for the computation of power flow. The active power loss $\left(P_{l}\right)$ in the line section connected between bus $i$ and bus $i+1$ may be stated as follows:

$$
P_{l}(i, i+1)=R_{i, i+1} \cdot \frac{P_{i}^{2}+Q_{i}^{2}}{\left|V_{i}\right|^{2}} .
$$

The total active power loss of the network $\left(P_{\text {loss }}\right)$ may be computed by summing up the losses of all the lines as follows:

$$
P_{\text {loss }}=\sum_{i=0}^{n-1} P_{l}(i, i+1)
$$

If a SC which has a size of $Q_{\mathrm{SC}}$ is connected to bus $i$, the inductive load in that bus changes from $Q_{D, i}$ to $\left(Q_{D, i}-Q_{s c, i}\right)$.

\subsection{Constraints}

\subsubsection{Bus Voltage Constraint}

$$
V_{i, \min } \leq V_{i} \leq V_{i, \max }, \quad i=1, \ldots, n,
$$

where $V_{i, \min }$ and $V_{i, \max }$ are the lower and upper limits of the voltage magnitude at the $i$ th bus and $n$ is the total number of buses of the network.

\subsubsection{Line Current Constraint}

$$
I_{k} \leq I_{k}^{\max }, \quad k=1, \ldots, n_{\mathrm{br}},
$$

where $I_{k}$ represents the current in the $k$ th line and $I_{k}^{\max }$ is the maximum loading of the $k$ th line.

$$
\begin{aligned}
& \text { 2.3.3. Shunt Capacitor Rating Constraint } \\
& \qquad Q_{\mathrm{SC}, i}^{\min } \leq Q_{\mathrm{SC}, i} \leq Q_{\mathrm{SC}, i}^{\max }, \quad i=2, \ldots, N,
\end{aligned}
$$

where $Q_{S C, i}^{\min }$ and $Q_{S C, i}^{\max }$ are the minimum and maximum reactive power limits, respectively, of SC at the $i$ th bus.

\subsubsection{Total Compensation Constraint}

$$
\sum_{i=1}^{n_{\mathrm{SC}}} Q_{\mathrm{SC}, i} \leq 0.7^{*} \sum_{j=1}^{n_{l}} Q_{D, j},
$$

where $n_{l}$ is the number of load buses of the network.

\subsubsection{System Power Factor Constraint}

$$
\mathrm{PF}_{\text {min }} \leq \mathrm{PF}_{\text {overall }} \leq \mathrm{PF}_{\max },
$$

where $\mathrm{PF}_{\text {overall }}$ is the network overall power factor and $\mathrm{PF}_{\text {min }}$ and $\mathrm{PF}_{\max }$ are the lower and upper limits of the network power factor, respectively.

\section{Formation of Proposed Technique}

3.1. Overview of SFS. Stochastic fractal search (SFS) is a relatively new metaheuristic optimization algorithm, which is inspired by the growing phenomenon of nature [34]. It uses the mathematical idea of well-known fractal theory for imitating this phenomenon. Like other population-based algorithms, SFS adopts a group of searching points, which is randomly initialized into the search region, for seeking the optimum solution. An $\mathbf{X}$ matrix defined as in equation (14) represents the searching group. Each point is referred to as a candidate solution to the designed optimization problem and involves a specific fitness value. New points are created by performing two phases, i.e., diffusion and update phases. New points are assessed, in each phase, and updated according to their fitness function values. In addition, the best point in the group is also determined after the execution per phase. The searching phases of SFS can be generally described as follows:

$$
\mathbf{X}=\left[\begin{array}{cccc}
x_{1,1} & x_{1,2} & \ldots & x_{1, D} \\
x_{2,1} & x_{2,1} & \ldots & x_{2, D} \\
\vdots & \vdots & \ddots & \vdots \\
x_{N P, 1} & x_{N P, 1} & \ldots & x_{N P, D}
\end{array}\right]
$$

where $D$ is the dimension of the designed problem and NP is the number of points in the group.

3.1.1. Diffusion Phase. To improve the probability of achieving the global optimum and avoid being trapped in 


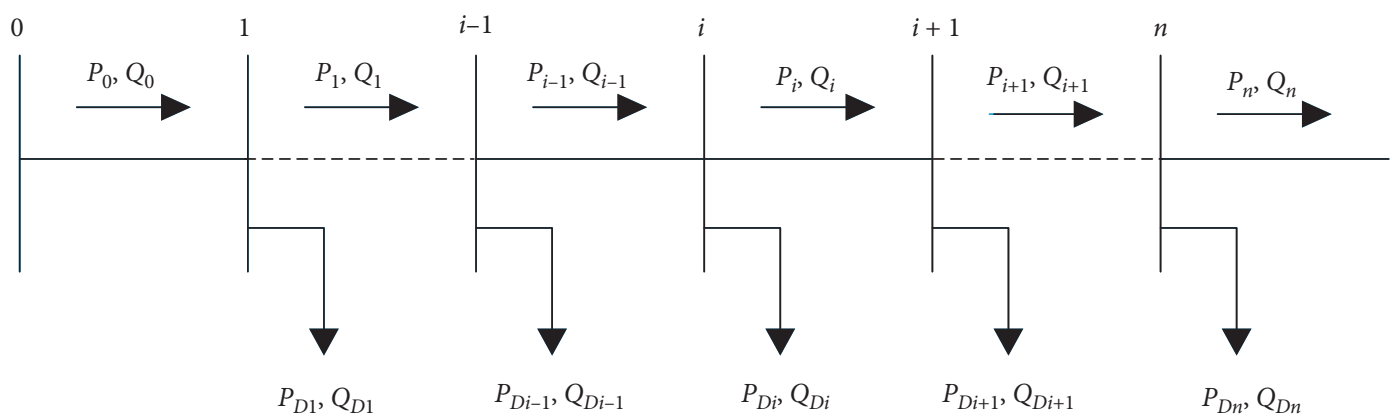

FIGURE 1: Representation of a single-line radial feeder.

local optima, each point is forced to diffuse into its vicinity. For creating new points, the diffusion process can be mathematically modeled with the application of the Gaussian distribution as the two following equations:

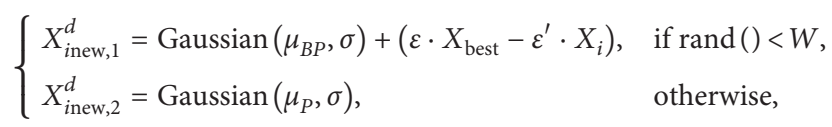

where $W$ is optional factor helping to choose the Gaussian walks for solving the problem; $X_{\text {inew }}^{d}$ is the newly amended location of $X_{i}$ at the $d$ th diffusion; $X_{i}$ and $X_{\text {best }}$ correspond to the locations of the point $X_{i}$ and the best point in the group; $\varepsilon$ and $\varepsilon^{\prime \prime}$ are the random numbers belonging to $[0,1]$; $\mu_{B P}$ and $\mu_{P}$ are parameters related to the Gaussian distribution, in which $\mu_{B P}=B P$ and $\mu_{P}=P_{i}$; and the standard deviation $\sigma$ can be computed as

$$
\sigma=\left|\frac{\log (g)}{g} \cdot\left(X_{i}-X_{\text {best }}\right)\right|,
$$

where $g$ indicates the generation number.

3.1.2. Updating Phase. The SFS uses two statistical procedures for the updating phase. The first statistical procedure impacts on each point vector index while the influence of the second one is on all points.

(1) The first statistical procedure: first, all points are ranked by using the following equation:

$$
P a_{i}=\frac{\operatorname{rank}\left(X_{i}\right)}{N P}
$$

where rank $\left(X_{i}\right)$ manifests the rank of the searching point $X_{i}$ in the group. Considering each point $X_{i}$, the $j$ th component of $X_{i}$ is only updated according to equation (18), if the term $P a_{i}<\varepsilon(\varepsilon \in[0,1])$ is met. Otherwise, no action is taken.

$$
X_{i}^{\prime}(j)=X_{j}(j)-\varepsilon \cdot\left(X_{h}(j)-X_{i}(j)\right)
$$

where $X_{i}^{\prime}$ implies the newly amended location of $X_{i}$ and $X_{j}$ and $X_{h}$ are points randomly picked in the group.

(2) The second statistical procedure: ranking all points from the first procedure according to equation (17) is firstly made. The term $P a_{i}<\varepsilon$ is then checked. If the term is met, the present location of $X_{i}^{\prime}$ will be updated based on equation (19). Otherwise, there will be no update on $X_{i}^{\prime}$.

$$
\begin{cases}X_{i}^{\prime \prime}=X_{i}^{\prime}-\widehat{\varepsilon} \cdot\left(X_{h}^{\prime}-X_{\text {best }}\right), & \text { if } \varepsilon^{\prime} \leq 0.5, \\ X_{i}^{\prime \prime}=X_{i}^{\prime}+\widehat{\varepsilon} \cdot\left(X_{h}^{\prime}-X_{j}^{\prime}\right), & \text { if } \varepsilon^{\prime}>0.5,\end{cases}
$$

where $X_{i}^{\prime \prime}$ points out the newly amended location of $X_{i}^{\prime}$ and $X_{j}^{\prime}$ and $X_{h}^{\prime}$ are points randomly picked among the points from the first procedure. Obviously, $X_{i}^{\prime}$ will be replaced by $X_{i}^{\prime \prime}$, if its fitness value is better.

3.2. Quasiopposition-Based Learning (QOBL). The theory of opposition-based learning (OBL) was first proposed for machine intelligence by Tizhoosh in 2005 [54]. Three years later, Rahnamayan et al. [55] successfully applied this theory to the differential evolution algorithm, which became an important prerequisite for further research studies on improving the performance of soft computing techniques, specifically in computation efficient and convergence speed. The strategy of OBL is to consider simultaneously existing guess and its opposite guess so that a better approximation for an existing candidate solution can be achieved. The study in [56] proved that a candidate solution with an OBL scheme has a better chance of being closer to the global optimum than that with random a scheme. Furthermore, the theory of OBL has been further extended to QOBL [57], which exposes that a quasiopposite point is more likely to be closer to the global optimum than an opposite point. So, QOBL is more capable of improving the convergence speed. Notably, in very recent research studies, QOBL has been utilized to enhance the performance of different metaheuristic algorithms such as quasioppositional chaotic grey wolf optimizer (QOCGWO) [58] and quasioppositional chaotic symbiotic organism search (QOCSOS) [59]. 
Some mathematical definitions utilized in QOBL can be described as follows.

3.2.1. Opposite Number and Opposite Point. Let $r \in[a, b]$ be a real number in a one-dimensional space, and then its opposite number $r^{o}$ is defined by equation (20). Similarly, let $R=\left(r_{1}, r_{2}, \ldots, r_{m}\right)$ be a point in a $m$-dimension space, where $r_{1}, r_{2}, \ldots, r_{m} \in \mathfrak{R}$ and $r_{i} \in\left[a_{i}, b_{i}\right] \forall i \in\{1,2, \ldots, m\}$. Its opposite point $R^{o}=\left(r_{1}^{o}, r_{2}^{o}, \ldots, r_{m}^{o}\right)$ may be defined by equation (21):

$$
\begin{gathered}
r^{o}=a+b-r, \\
r_{i}^{o}=a_{i}+b_{i}-r_{i} .
\end{gathered}
$$

3.2.2. Quasiopposite Number and Quasiopposite Point. The quasiopposite number $r^{q o}$ defined as the number between the center of the search space $c$ and the opposite number $r^{o}$ can be determined by equation (22). In the case of $m$-dimension space, the quasiopposite point $R^{q o}=\left(r_{1}^{q o}, r_{2}^{q o}, \ldots, r_{m}^{q o}\right)$, where $r_{1}^{q o}, r_{2}^{q o}, \ldots, r_{m}^{q o} \in \Re$ and $r_{i}^{q o} \in\left[a_{i}, b_{i}\right] \forall i \in\{1,2, \ldots, m\}$, is expressed by equation (23).

$$
\begin{aligned}
& r^{q o}=\operatorname{rand}\left(c, r^{o}\right), \quad \text { where } c=\frac{a+b}{2}, \\
& r_{i}^{q o}=\operatorname{rand}\left(c_{i}, r_{i}^{o}\right), \quad \text { where } c_{i}=\frac{a_{i}+b_{i}}{2} .
\end{aligned}
$$

3.3. Implementation of $Q O B L$. According to our literature survey, QOBL has been commonly utilized to improve the overall performance of population-based metaheuristic search algorithms in two aspects, namely, population initialization and generation jumping. Regarding population initialization, the initial group with NP points is randomly generated within the search space. Afterward, quasiopposite group $\mathbf{R}^{q o}$ is obtained using equation (23), and the NP fittest points are selected as the initial group from the union of $\mathbf{X}$ and $\mathbf{R}^{q o}$. Following the evolutionary process of the algorithm, a new candidate solution with a better fitness value can be acquired thanks to QOBL-based generation jumping. The QOBL-based generation jumping is related to a parameter $j_{r}$ (named as jumping rate), which determines whether to retain an existing candidate solution or jump over to a quasiopposite solution.

The initialization of quasiopposite group is illustrated by the pseudocode in Algorithm 1.

3.4. Chaotic Local Search. In this study, the CLS strategy has been further applied to the current best group of the proposed ISFS with the intent to explore the region around the current best solutions. The chaotic variables obtained by logistic map can be mapped back to the search space using the following equation:

$$
v_{i+1}=X_{\text {best }}+\left(\mathrm{cu}_{i+1}-0.5\right)\left(X_{j}-X_{k}\right)
$$

where $v_{i+1}$ is the newly generated point at the $(i+1)$ th iteration; $X_{\text {best }}$ is the best point of the proposed ISFS; $\mathrm{Cu}_{i+1}$ is a chaotic number between 0 and 1 at $(i+1)$ th iteration; and $X_{j}$ and $X_{k}$ are two points randomly picked up from the existing best group. Notably, the initial value of the chaotic variable is assigned by using a random function rand $(0,1)$ as suggested by Xiang et al. [60]. In each iteration of CLS, the fitness value is computed for the new point $v_{i+1}$, and it is updated only if it offers better fitness than the current best point. The stopping condition of CLS occurs when the $K$ limit is reached.

There are many categories of chaotic maps reported in the literature [42, 46-48]. In the current research, we have adopted the well-known logistic map to generate a chaotic number in CLS. The mathematical formula of the logistic map is described as follows:

$$
\mathrm{cu}_{i+1}=\mu \cdot \mathrm{cu}_{i} \cdot\left(1-\mathrm{cu}_{i}\right)
$$

where $\mathrm{cu}_{i} \in(0,1) \forall i \in\{0,1,2, \ldots\}$ and $\mu \in(0,4]$. The parameter $\mu$ in equation (25) helps to control the behavior of the logistic map as simulated in Figure 2. Observing Figure 2, at the value $\mu=4$, the logistic function reveals overall chaotic behavior and so we have chosen this value for the parameter $\mu$. Generation of chaotic numbers via the logistic map is depicted in Figure 3.

3.5. Proposed ISFS. To establish the proposed ISFS algorithm, two strategies, namely, QOBL and CLS, are integrated into the structure of the original SFS algorithm. Pertaining to the search process, ISFS adopts a randomly generated group of points $\mathbf{X}$. Then, the quasiopposite points $R^{q o}$ of the initial group are produced using the QOBL strategies. The NP of best points with corresponding best fitness values is elected from the union of $\mathbf{X}$ and $R^{q o}\left\{X \cup R^{q o}\right\}$ as an initial group. Next, the two iterative procedures of diffusing and updating of the SFS algorithm are performed. Afterward, the QOBL strategy is applied again based on the jumping probability $j_{r}$. Finally, the CLS is activated to acquire the best point. The process repeats until the maximum number of generations is reached (Algorithm 2).

\section{Implementation of ISFS to OCP Problem}

In this research, the proposed ISFS has been applied to the OCP problem solving in two different scenarios. Specifically, in scenario I, we have investigated the problem with a traditional cost objective function like most previous studies to make a performance comparison analysis. Meanwhile, for the proposed scenario II, a modified cost objective function considering a practical 24-hour load profile has been adopted for investigations.

4.1. Initialization of Search Group. A group of NP points is represented by a matrix $\mathbf{X}=\left[X_{1}, X_{2}, \ldots, X_{N P}\right]^{T}$, in which each point $X_{d}(d=1, \ldots, \mathrm{NP})$ represents a solution vector of variables of locations and sizes of SCs. Considering the OCP 


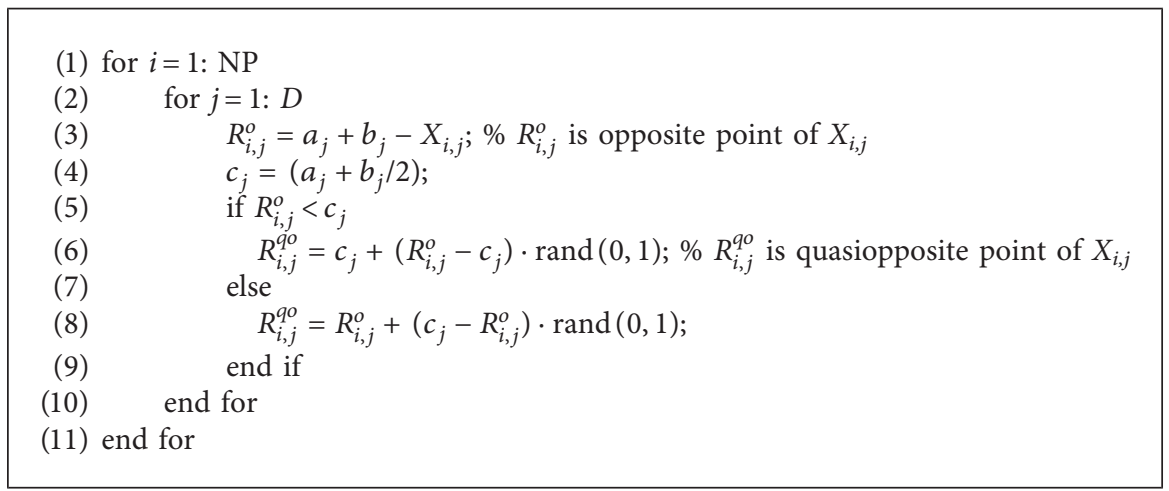

Algorithm 1: Pseudocode of QOBL.

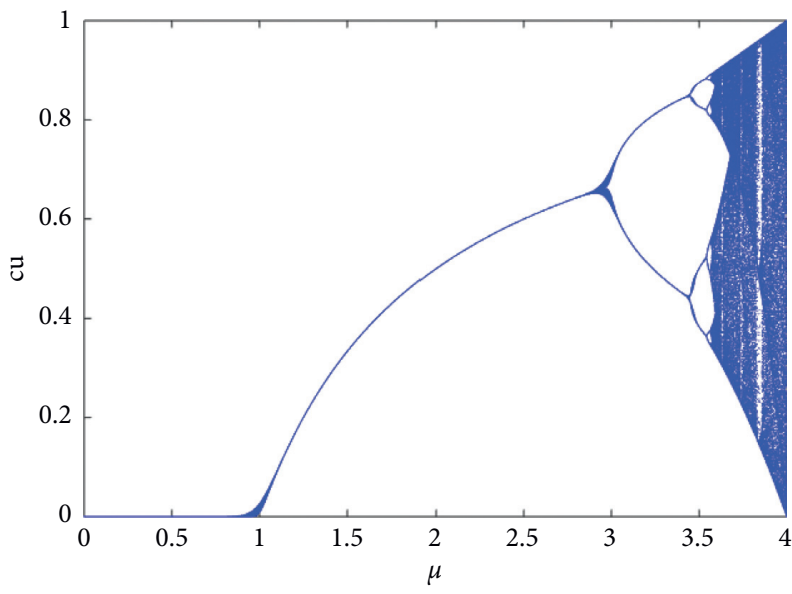

FIgURE 2: Bifurcation diagram of logistic map.

problem, solution vectors for scenarios I and II are formulated as in equations (26) and (27), respectively.

$$
\begin{aligned}
& X_{d}=\left[\operatorname{lo}_{\mathrm{SC}, 1}, \ldots, \operatorname{lo}_{\mathrm{SC}, n_{\mathrm{SC}}}, Q_{\mathrm{SC}, 1}, \ldots, Q_{\mathrm{SC}, n_{\mathrm{SC}}}\right] ; \quad d=1, \ldots, \mathrm{NP}, \\
& X_{d}=[\underbrace{Q_{\mathrm{SC} \text { in load level } 1}^{1}, \ldots, Q_{\mathrm{SC}, n_{\mathrm{SC}}}^{1}}_{\mathrm{kV}, 1} \cdots \underbrace{Q_{\mathrm{SC}, 1}^{i}, \ldots, \mathrm{Q}_{\mathrm{SC}, n_{\mathrm{SC}}}^{i}}_{\mathrm{kVArs} \text { in load level } i} \cdots \underbrace{\mathrm{Q}_{\mathrm{SC}, 1}^{l}, \ldots, Q_{\mathrm{SC}, n_{\mathrm{SC}}}^{l}}_{\mathrm{kVArsin} \text { load level } l}] ; \quad d=1, \ldots, \mathrm{NP},
\end{aligned}
$$

where $n_{\mathrm{SiC}}$ denotes the number of the switched SCs previously determined in scenario I and $l$ implies the number of load levels in a representative day as presented in Table 1. It is noted that the dimension of the solution vector $X_{d}$ for examining scenario II will be defined as the product of $n_{\mathrm{SiC}}$ and $l$.

In the ISFS, each point of the group is randomly initialized. The solution for the number of buses $\left(l_{\mathrm{SC}, i}\right)$ is initialized using equation (28).

$$
\operatorname{lo}_{\mathrm{SC}, i}=\operatorname{round}\left[\operatorname{lo}_{\mathrm{SC} \min , i}+\operatorname{rand}(0,1) \cdot\left(\operatorname{lo}_{\mathrm{SC} \max , i}-\operatorname{lo}_{\mathrm{SC} \min , i}\right)\right] \text {. }
$$

To treat the actual discrete capacitor size $\left(Q_{\mathrm{SC}, i}\right)$, we have proposed a new initialization process as follows: considering the actual discrete size of capacitor belongs to the range $\left[0, \ldots, Q_{\mathrm{SC} \text { max }}\right]$ with an increase step of $\Delta Q_{\mathrm{SC}}$. Therefore, the dimension of vector containing the discrete size values will be $N_{\max }=\left(\left(Q_{\mathrm{SC} \text { max }} / \Delta Q_{\mathrm{SC}}\right)+1\right)$. Firstly, we sort the discrete size values in ascending order and then we number the arranged discrete sizes from $\operatorname{Ind}_{\mathrm{Cmin}}$ to $\operatorname{Ind}_{\mathrm{Cmax}}$, which corresponds to a range of values from 1 to $N_{\max }$. Clearly, each component of discrete size vector can be determined via an index Ind $_{\mathrm{SC}}$. For ensuring randomization in the initialization process of discrete size variable, equation (31) below must be applied. After initialization with equation (31), equation (32) can be used for estimating the actual discrete capacitor size values $\left(Q_{\mathrm{SC}, i}\right)$. A group of relevant mathematical equations can be listed as follows: 


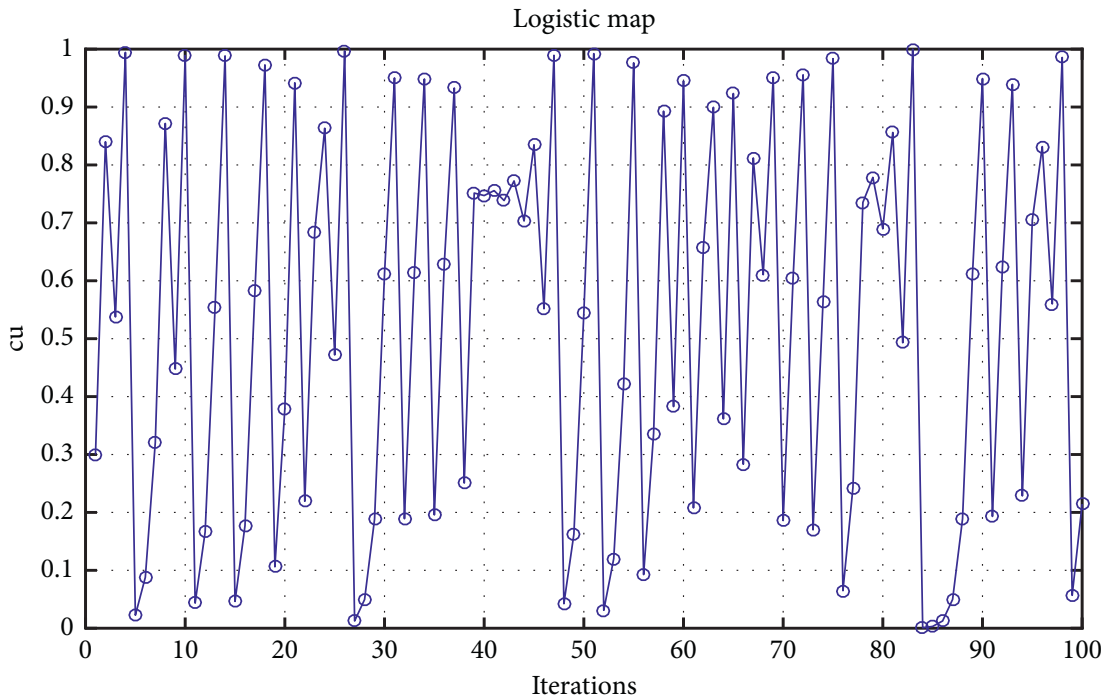

FIGURE 3: Visualization of logistic map.

(1) Define control parameters ( $D, \mathrm{NP}, \max \_$iter, $\left.\mathrm{MDN}, j_{r}, K\right)$;

(2) Initialize uniformly distributed random group $\mathbf{X}$;

$\% * \mathrm{QOBL}$ - based group initialization $* \%$

(3) Execute Algorithm 1 to acquire quasiopposite group $R^{q o}$

(4) Compute fitness value for the combined group $\mathbf{X}_{\mathbf{c}}=\left\{X \cup R^{q o}\right\}$;

(5) Elect NP fittest points from $\mathbf{X}_{\mathbf{c}}$ as initial group;

(6) Set the iteration counter iter $=1$;

(7) while (iter $<$ max_ter)

$\% *$ Diffusion process $* \%$

(8) for $i=1$ : NP

(9) for $j=1: \mathrm{MDN}$

(10) New point $X_{\text {inew }}^{d}$ is created via the Gaussian walk using equation (15);

(11) end for

(12) Compute fitness value for $X_{\text {inew; }}$;

(13) Update $X_{\text {inew }}^{d}$ if its fitness is better;

(14) end for

(15) Identify $X_{\text {best }} ; \% X_{\text {best }}$ is the best point of group;

$\% *$ First updating process $* \%$

(16) Rank all the points;

(17) Assign each point with a probability of $P_{a_{i}}$;

(18) for $i=1$ : NP

(19) for $j=1$ : size $\left(X_{\text {inew }}, 2\right)$

(20) if rand $(0,1)>P_{a_{i}}$

(21) Calculate new point $X_{\text {inew }}^{\prime}$ according to equation (18);

(22) else

(23) Do nothing

(24) end if

(25) end for

(26) end for

(27) Compute fitness value for $X_{\text {inew; }}^{\prime}$;

(28) Update $X_{\text {inew }}{ }^{\prime}$ if its fitness value is better;

(29) Update $X_{\text {best }}$;

$\% *$ Second updating procedure $* \%$

(30) Rank all the points from the first process;

(31) Assign each point with a probability of $P_{a_{i}}$;

(32) for $i=1$ : NP

(33) if rand $(0,1)>P_{a_{i}}$

Algorithm 2: Continued. 


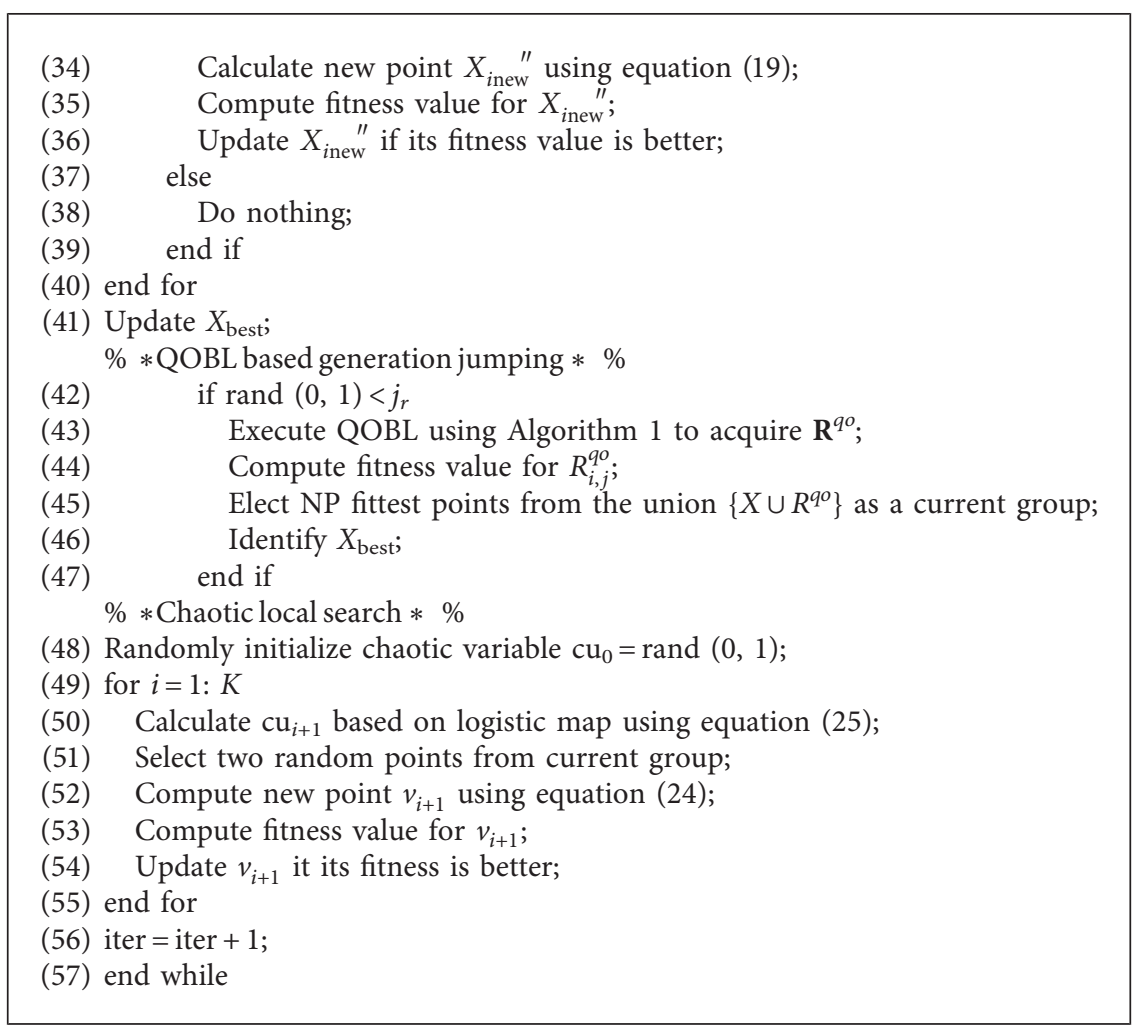

Algorithm 2: Pseudocode of the proposed ISFS algorithm.

$$
\begin{aligned}
Q_{\mathrm{SC}}= & {\left[0, \ldots, Q_{\mathrm{SC} \max }\right], } \\
\operatorname{Ind}_{\mathrm{SC}}= & {\left[\operatorname{Ind}_{\mathrm{SC} \min }, \ldots, \operatorname{Ind}_{\mathrm{SC} \max }\right] } \\
= & {\left[1, \ldots, N_{\max }\right], } \\
\operatorname{Ind}_{\mathrm{SC}, i}= & \operatorname{round}\left[\operatorname{Ind}_{\mathrm{SC} \min , i}+\operatorname{rand}_{1}\right. \\
& \left.\times\left(\operatorname{Ind}_{\mathrm{SC} \max , i}-\operatorname{Ind}_{\mathrm{SC} \min , i}\right)\right], \\
i= & 1, \ldots, n, \\
Q_{\mathrm{SC}, i}= & Q_{\mathrm{SC}}\left(\operatorname{Ind}_{\mathrm{SC}, i}\right),
\end{aligned}
$$

where rand $_{1}$ indicates a uniformly distributed random number belonging to $[0,1] ; \operatorname{Ind}_{\mathrm{SC}, i}$ is an index representing the discrete size of the $i$ th capacitor; and $\operatorname{Ind}_{\mathrm{SCmin}, i}$ and Ind $_{\mathrm{SCmax}, i}$ are, respectively, the lower and upper limits of the index that deputizes the available discrete size value of the $i$ th capacitor.

4.2. Fitness Function Formulation. For scenario I, each point in the initialized group is evaluated by using a fitness function as defined in equation (33a); meanwhile, equation (33b) is utilized to evaluate the points of the group when considering scenario II.

$$
\begin{gathered}
\left\{F_{C}=\text { Cost }+ \text { Penalties; in Scenario } I,\right. \\
\left\{F_{M C}=\right.\text { MC + Penalties; in Scenario II, }
\end{gathered}
$$

in which

$$
\left\{\begin{array}{l}
\text { Penalties }=\lambda_{v}+\lambda_{p f}+\lambda_{i}+\lambda_{c}, \\
\lambda_{v}=\zeta_{v} \cdot\left[\sum_{i=1}^{n} \max \left(0,\left|V_{i}\right|-V_{i, \max }\right)+\sum_{i=1}^{n} \max \left(0, V_{i, \min }-\left|V_{i}\right|\right)\right], \\
\lambda_{p f}=\zeta_{p f} \cdot\left[\max \left(0, \mathrm{PF}_{\text {overall }}-\mathrm{PF}_{\max }\right)+\max \left(0, \mathrm{PF}_{\min }-\mathrm{PF}_{\text {overall }}\right)\right], \\
\lambda_{i}=\zeta_{i} \cdot\left[\sum_{k=1}^{n_{b r}} \max \left(0, I_{k}-I_{k}^{\mathrm{rated}}\right)\right] \\
\lambda_{c}=\zeta_{c} \cdot\left[\max \left(0, \sum_{i=1}^{n_{S C}} \mathrm{Q}_{C, i}-\sum_{j=1}^{n_{l}} Q_{D, j}\right)\right]
\end{array}\right.
$$

where Cost and MC are, respectively, the traditional and modified cost objective functions and Penalties is the penalty function that is burdened to the objective function with purpose to prevent a search point from the infeasible solution region. Consequently, the optimal solution is established when there are no constraints violated and the objective function is minimized. The terms $\zeta_{v}, \zeta_{p f}, \zeta_{i}$, and $\zeta_{c}$ are, respectively, penalty factors for bus voltages, system 
overall power factor, branch currents, and SC penetration. In this study, we set the penalty factors at $10^{6}$ based on the repeated trials.

In order to calculate the fitness value of each point, the solutions of the power flow problem are needed, and therefore Matpower toolbox 6.0 [53] is applied for the power flow problem.

4.3. Overall Procedure. The flowchart of the proposed ISFS algorithm for dealing with the OCP problem is provided in Figure 4.

4.4. Scheme for Daily Operation Scheduling of Switched Capacitor. The continuous variation of load demand causes a change in bus voltage, leading to a change in reactive power demand, and thus the solution of fixed reactive compensation cannot meet this situation. Compensating variable reactive power demand according to the daily load variation can be implemented by employing switched capacitors. A suitable choice of fixed and switched SCs enables us to prevent unwanted voltage values and to mitigate the daily network losses. In contrast, an inappropriate dispatching plan of switched capacitors after the variation of load demand may result in power loss increase and voltage limit violation. For economic analysis, the network might suffer from significant energy loss costs due to increased power losses. Thus, with the available load forecast data for the next 24-hour cycle, the on/off operations at each hour of the following day can be estimated in anticipation of keeping power losses at the lowest possible level so that the minimum energy loss costs are achieved. In this scenario, we proposed a modified cost function for investigating the on/off scheduling plans of switched SCs with a practical 24-hour load profile. Our proposed cost function includes the annual energy loss cost, in which load level duration data as well as the installation, operation, and maintenance costs of SCs are provided in Table 1 . The variation of load demand within a 24-hour cycle is illustrated in Figure 5. The scheme for the daily on/off scheduling of the switched SCs is described in Algorithm 3.

\section{Numerical Results and Discussion}

The performance of the proposed ISFS algorithm was tested on three IEEE benchmark RDNs including one mediumscale 69-bus network and two large-scale 119- and 152-bus networks with two examined scenarios. To evaluate the effectiveness of the proposed ISFS algorithm, we also applied the original SFS algorithm to solve the OCP problem for result comparison. For each test scenario, both SFS and ISFS were run for 50 independent trials to obtain the best outcome. The proposed method was implemented on MATLAB R2016a platform installed on an Intel core i5-3337U, $1.80 \mathrm{GHz}$ processor, and $8 \mathrm{~GB}$ RAM.

To assess the computing performance of the different algorithms, we propose a new index named as enhancement index-EI (\%)-for estimating the improvement level of the

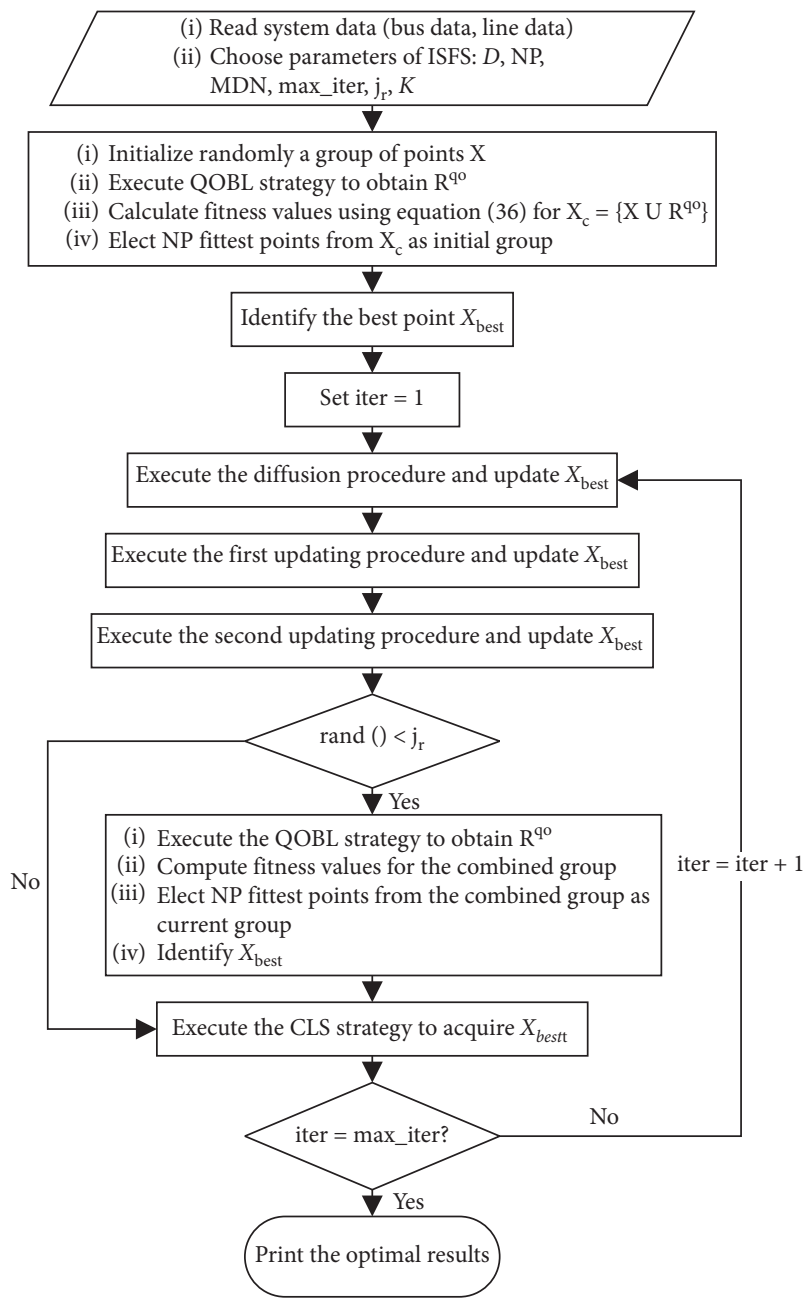

FIgURE 4: Flowchart of the proposed ISFS.

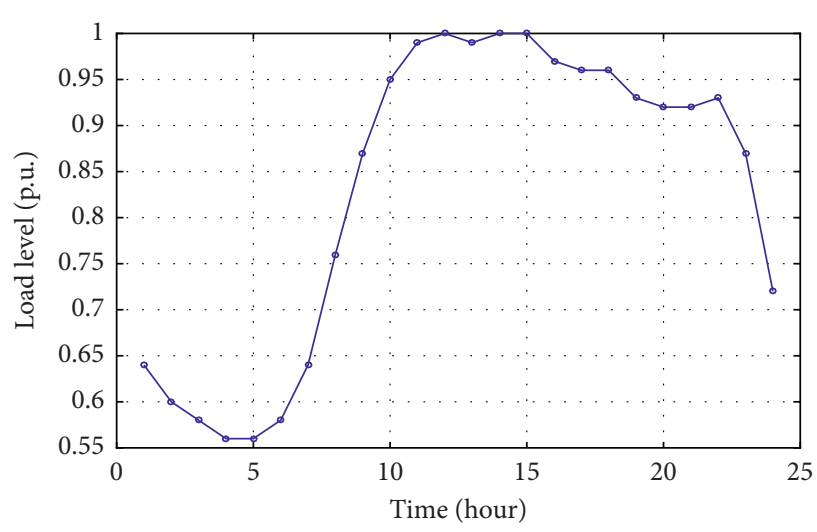

Figure 5: Variation of daily load demand.

best solution reported from a new algorithm as compared with the best solution found so far (best-so-far).

$$
\mathrm{EI}=\frac{\mathrm{BSF}-\mathrm{BC}}{\mathrm{BSF}} \cdot 100,
$$

where BSF (\$/year) is the best-so-far cost reported and BC (\$/year) is the best cost obtained by other algorithms. 
(1) Determine the optimum sites and sizes of the fixed and switched SCs by applying the proposed method for each of three loading levels: 50,75, and 100\% of the base peak loads. The obtained sites of the switched SCs are used for the following analysis;

(2) Read the load profiles from the forecasted data of the 24 -hour load demand. Table 1 provides the detailed data of the forecasted load demand;

(3) Perform a 24-hour load flow analysis by using the proposed load flow technique to compute the total annual cost for the uncompensated case;

(4) Randomly initialize the switched SCs discrete sizes at the respective sites obtained from Step 1 by using equations (27) and (29)-(32);

(5) Compute the fitness value for each candidate solution using equation (33b) and determine the fittest solution based on their fitness values;

(6) while (iter $<$ max_iter)

(7) Execute the diffusion process for new candidate solutions creation. Compute fitness value for new solutions by using equation (33b) and update the best solution;

(8) Execute the first update procedure. Compute fitness values by using equation (33b) and update the best solution;

(9) Execute the second update procedure. Compute fitness values by using equation (33b) and update the best solution;

(10) $\quad$ if rand ()$<j_{r}$

(11) Create the new solutions based on the QOBL strategy in Algorithm 1;

(12) Compute fitness values by using equation (33b) and update the best solution;

(13) end if

(14) Execute the CLS strategy to acquire the best solution;

(15) $\quad$ iter $=$ iter +1 ;

(16) end while

(17) The optimum on/off operations of the switched SCs according to variable load demand with intent to total annual cost minimization are achieved by the proposed ISFS.

Algorithm 3: Daily on/off scheduling for the switched SCs.

\subsection{Assumptions, Control Parameters, and Constraints.} This study considers some assumptions for tackling the OCP as follows.

The test RDN is examined under balance operating conditions. Constant active and reactive load model is used for investigations. We neglect the effect of harmonics on the test network.

Regarding the parameter setting, the SFS has three main parameters, namely, the number of points NP; the maximum number of generations max_iter; and the maximum number of diffusions $\mathrm{MDN}$ as well as one additional parameter $W$ that needs to be predetermined. They can be fixed depending on the complexity of the designed problems. More specifically, the information for the setting of parameters for the SFS and the inequality constraints setting for the OCP problem are given in Table 2. Besides the mentioned algorithm parameters, the proposed ISFS algorithm has two more parameters related to the integrated enhancement tools, including jumping rate $j_{r}$ and local search limit $K$. They also need to be estimated in advance for the ISFS.

Notably, $j_{r}$ is known as an important parameter, controlling the convergence speed of ISFS. With a higher value of $j_{r}$ chosen, it provokes the algorithm to jump to a new outcome at a faster speed, thus causing premature convergence situation. Realizing this, a trial on the 119-bus network with the location and size examination of the fixed number of SCs of 9 was conducted with the intent to obtain a proper $j_{r}$ value. For this experiment, we first fixed $K$ at 1 and then varied $j_{r}$ from 0.1 to 0.9 with a step of 0.1 . The ISFS was run for 50 independent trials for each $j_{r}$ value. Figure 6 reveals mean fitness and standard deviation values for all 50 trials. Clearly, the proposed ISFS settled at the lowest mean fitness value at $j_{r}=0.3$ with the smallest standard deviation. Thus, the jumping rate $j_{r}$ was set at 0.3 for all the test scenarios of the paper.

For the next experiment, we also utilized the tested case in the 119-bus network for selecting the value of the parameter $K$. Similarly, the parameter $j_{r}$ remained fixed at 0.3 and the value of $K$ was varied from 2 to 30 for step 2 . We experimented with the ISFS by solving the test case for each value of $K$ for 50 separate trials. Mean fitness and standard deviation results for all 50 trials are shown in Figure 7. From the figure, it is observed that the ISFS is capable of finding the minimum mean fitness value at five different $K$ values, i.e., $K=10,16,20,26,30$. However, $K=20$ results in obtaining the smallest standard deviation. Therefore, we set $K$ at 20 for all investigations in this study.

5.2. IEEE 69-Bus Network. The first test network is a medium-scale standard 69-bus RDN including 69 buses and 68 branches with data given in [61]. This network is operated at a rated voltage level of $12.66 \mathrm{kV}$ with $100 \mathrm{MVA}$ base. It provides a total load demand of 3.8 MW and 2.69 MVAr. Before SC placement, the network suffers from a total loss of $225 \mathrm{~kW}$ and $102.16 \mathrm{kVAr}$ at $100 \%$ loading.

\subsubsection{Scenario 1: Traditional Cost Objective Function.} Once the OCP problem is examined, a controversial issue is that how many SCs connected will achieve an optimal level of penetration pertaining to reactive compensation, meaning that this penetration will lead to a minimum total annual cost while satisfying all relevant constraints. This has not 
TABLE 2: Algorithm parameters and inequality constraint settings.

\begin{tabular}{lccc}
\hline Item & 69-bus test system & 119-bus test system & 152-bus test system \\
\hline $\mathrm{NP}$ & 10 & 15 & 30 \\
Max_iter & - & - & - \\
Scenario 1 & 50 & 500 & 100 \\
Scenario 2 & 100 & 2000 & 500 \\
MDN & 2 & 5 & 2 \\
$W$ & 0.75 & $0.9 \leq\left|V_{i}\right| \leq 1.05$ & 0.5 \\
Bus voltage limit & $0.9 \leq\left|V_{i}\right| \leq 1.05$ & $0.9 \leq \mathrm{PF}_{\text {overall }} \leq 1$ & $0.9 \leq\left|V_{i}\right| \leq 1.05$ \\
Power factor limit & $0.9 \leq \mathrm{PF}_{\text {overall }} \leq 1$ & $2^{*}$ & $0.9 \leq \mathrm{PF}_{\text {overall }} \leq 1$ \\
Number of SCs to be connected & & $0-1500 \mathrm{kVAr}$ with an increment step of $50 \mathrm{kVAr}$ & $2^{*}$ \\
Actual capacitor size & &
\end{tabular}

The sign " $*$ " implies the optimal number of SCs to be chosen.

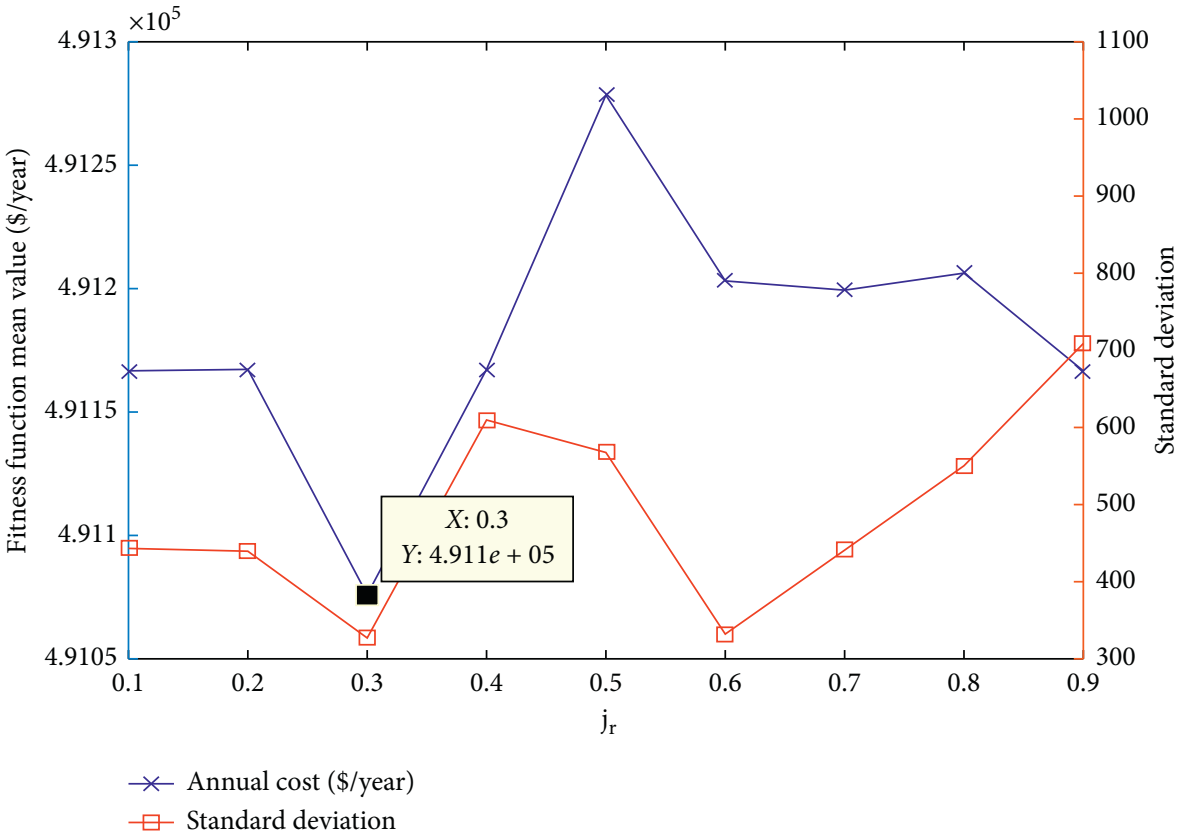

Figure 6: Influence of the jumping rate parameter $j_{r}$.

been well addressed in previous studies when the considered number of SCs is often assumed for test networks.

Our study has conducted an extensive experiment to cope with this issue. By implementing the experiment for this test instance, the change in the percentage of annual cost saving induced by the different SC numbers as well as the corresponding penetration level of these SC numbers is shown in Figure 8 with the aid of the ISFS optimization algorithm. From Figure 8, it can be observed that the connection of two SCs with a total size of 1.4 MVAr results in the highest percentage of saving corresponding to the minimum total cost as compared to the different numbers of SC connection. Thus, only 2 SC placements have been considered for the 69-bus network.

The optimal placements and reactive powers of SCs along with the network performance indexes at different load levels acquired by the ISFS are provided and compared with IHA [19] as shown in Table 3. Fixed and switched capacitors' ratings and placements according to load demand variation are given in Table 3 as well. It can be observed from the table that in the $100 \%$ load level, the ISFS suggests the optimal set of buses for SC installation is $\{20,61\}$ and the corresponding optimal sizes of SCs on these buses are $\{250,1150\} \mathrm{kVAr}$. Notably, the proposed ISFS algorithm nominates the IHA [19] algorithm in terms of computational performance at all test load levels due to the gain of lower annual costs.

The obtained numerical results pertaining to the optimal number of SCs by employing the proposed ISFS algorithm are provided in Table 4, and they are compared with other well-established optimization algorithms such as fuzzy GA [26], DE [11], FA [8], PSO [4], heuristic method (HM) [62], IHA [19], DSA [29], TLBO [12], and SFS for proving its effectiveness and robustness. It can be seen from Table 4 that in the $100 \%$ loading case, before optimal compensation, the network has a total active power loss of $225.0006 \mathrm{~kW}$, a minimum bus voltage of 0.9092 p.u. at bus number 65 , and network overall power factor of 0.821 lagging. For cost 


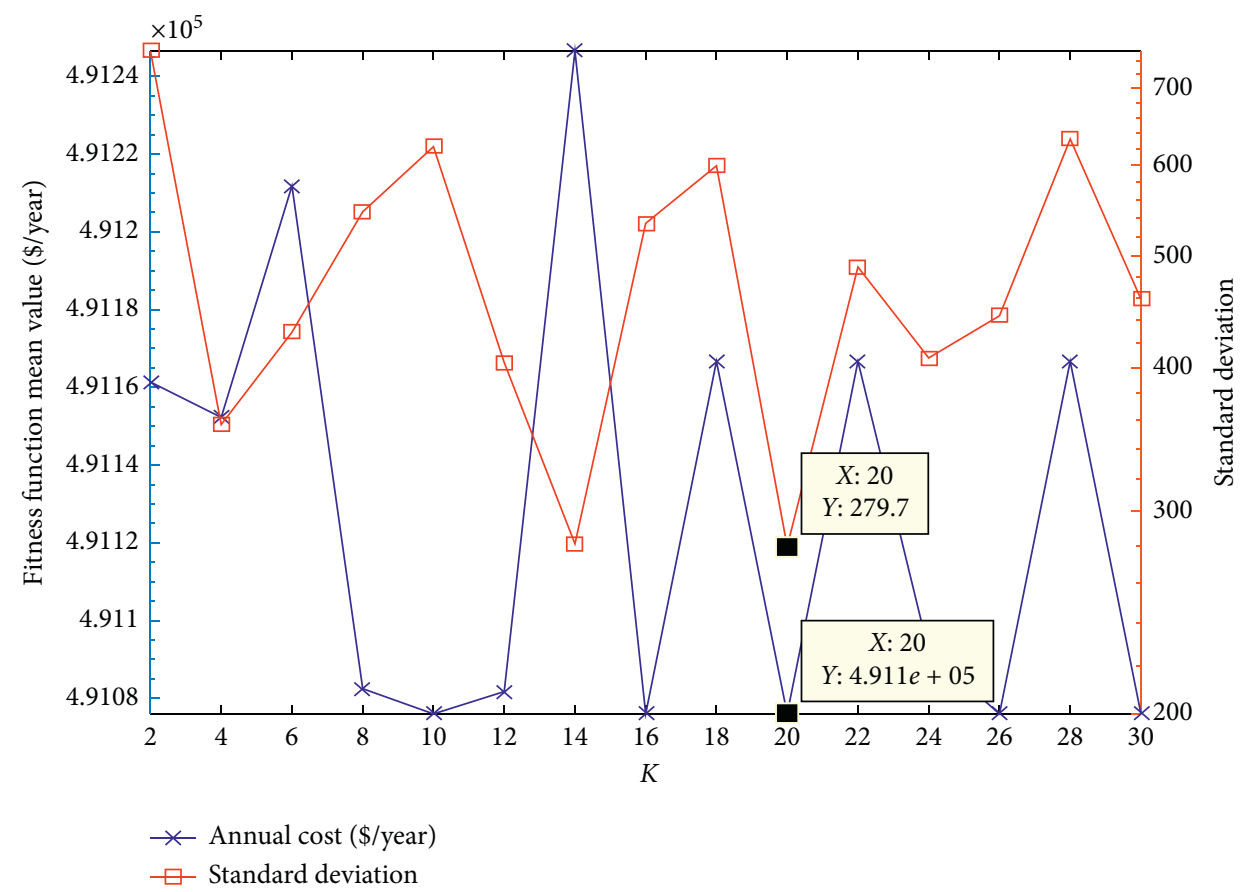

Figure 7: Impact for the local search limit parameter $K$ with $j_{r}=0.3$.

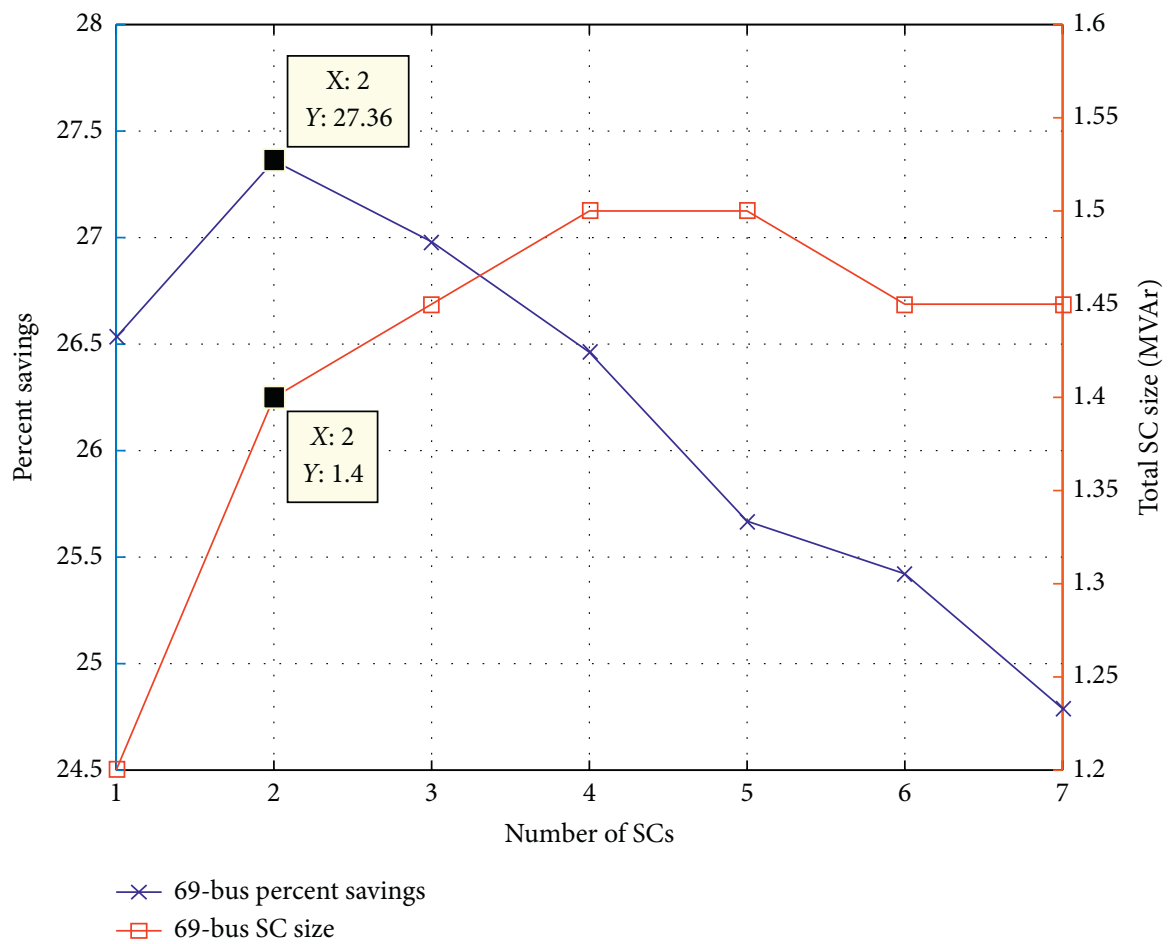

FIGURE 8: Effect of different numbers of SCs on performance of 69-bus network.

analysis, total active power loss causes an annual energy loss cost of $\$ 118,260.3$. After SC placement by the proposed ISFS method, the power loss is reduced to $147.7621 \mathrm{~kW}$, the minimum voltage is enhanced to 0.9289 p.u., and the network overall power factor is corrected to 0.9453 lagging. Besides, the total annual cost including SC installation, operation, and maintenance costs declines to $\$ 85,903.75$. So, the net saving for this case is $\$ 32,356.5$, i.e., $27.3 \%$ yearly economic benefit can be accomplished by reactive power compensation. Although yearly cost objective values yielded by the proposed ISFS and original SFS methods are the same, the ISFS requires fewer number of iterations than the SFS to 
TABLE 3: Simulation results and comparison for 69-bus network at different loading conditions.

\begin{tabular}{|c|c|c|c|}
\hline \multirow{2}{*}{ Items } & \multirow{2}{*}{ Uncompensated } & \multicolumn{2}{|c|}{ Compensated } \\
\hline & & IHA [19] & Proposed ISFS \\
\hline \multicolumn{4}{|c|}{$50 \%$ load level } \\
\hline Site and installed kVAr & - & $(61,550)$ & $(61,550)$ \\
\hline Total kVAr & - & 550 & 550 \\
\hline Losses in $\mathrm{kW}$ & 51.6064 & 36.0528 & 36.0528 \\
\hline Loss reduction (\%) & - & 30.14 & 30.14 \\
\hline Minimum voltage (p.u.) & 0.9566 & 0.9649 & 0.9649 \\
\hline $\mathrm{PF}_{\text {overall }}$ & 0.8184 & 0.9218 & 0.9218 \\
\hline Annual cost (\$/year) & $27,124.29$ & $22,319.36$ & $22,319.36$ \\
\hline Net saving (\$/year) & - & $4,804.93$ & $4,804.93$ \\
\hline$\%$ saving & - & 17.71 & 17.71 \\
\hline \multicolumn{4}{|c|}{$75 \%$ load level } \\
\hline Site and installed kVAr & - & $(61,900)$ & $(20,150) ;(61,850)$ \\
\hline Total kVAr & - & 900 & 1000 \\
\hline Losses in $\mathrm{kW}$ & 121.0301 & 83.0542 & 80.80 \\
\hline Loss reduction (\%) & - & 31.37 & 33.23 \\
\hline Minimum voltage (p.u.) & 0.9335 & 0.9475 & 0.9473 \\
\hline $\mathrm{PF}_{\text {overall }}$ & 0.8198 & 0.93 & 0.9405 \\
\hline Annual cost (\$/year) & $63,613.40$ & $48,773.33$ & $48,713.58$ \\
\hline Net saving (\$/year) & - & $14,840.07$ & $14,899.81$ \\
\hline$\%$ saving & - & 23.32 & 23.42 \\
\hline \multicolumn{4}{|c|}{$100 \%$ load level } \\
\hline Site and installed kVAr & - & $(21,350) ;(61,1350)$ & $(20,250) ;(61,1150)$ \\
\hline Total kVAr & - & 1700 & 1400 \\
\hline Losses in $\mathrm{kW}$ & 225.0006 & 146.8779 & 147.7621 \\
\hline Loss reduction (\%) & - & 34.72 & 34.33 \\
\hline Minimum voltage (p.u.) & 0.9092 & 0.9322 & 0.9289 \\
\hline $\mathrm{PF}_{\text {overall }}$ & 0.821 & 0.9656 & 0.9453 \\
\hline Annual cost (\$/year) & $118,260.3$ & $86,939.05$ & $85,903.75$ \\
\hline Net saving (\$/year) & - & $31,321.27$ & $32,356.5$ \\
\hline$\%$ saving & - & 26.48 & 27.36 \\
\hline Injected $\mathrm{kVAr}$ by proposed ISFS & & $\begin{array}{c}\text { Fixed: }(61,550) \\
\text { Switched: }(20,250) ;(61,600)\end{array}$ & \\
\hline
\end{tabular}

achieve this solution, as illustrated in Figure 9. Clearly, ISFS shows a faster convergence speed as compared to SFS in this case. Furthermore, most performance statistics obtained from ISFS are better than those from SFS, except for the average execution time. The average execution time of ISFS is longer than that of SFS due to the time for the extensive search process of integrated enhancement strategies. However, this reported time is the time for the entire search procedure, i.e., execution time for all the predefined loops for a comparative analysis. Indeed, ISFS finds the optimal solution with much fewer iterations than SFS; thus, its time to reach the best solution is faster than that of SFS.

Regarding performance comparison, the ISFS yields the best yearly cost of $\$ 85903.75$, which is the lowest cost among the previously reported costs from fuzzy GA [26] $(\$ 92,179.5)$, DE [11] $(\$ 89,913.4)$, FA [8] $(\$ 86,210)$, PSO [4] $(\$ 90,108.5)$, HM [62] $(\$ 88,901.1)$, IHA [19] $(\$ 86,122.1)$, DSA [29] $(\$ 88,123.2)$, and TLBO [12] $(\$ 87,781.56)$. For further analysis, we utilized an EI to evaluate the improvement level of the reported best solutions from the different methods in comparison with the best-so-far solution. In this case, the best-so-far solution is provided by the authors in [19] using the IHA. As seen from Table 4, only our two ISFS and SFS algorithms receive the EIs with positive values, whereas the remaining algorithms get the negative EIs. This means that the final solutions obtained by ISFS and SFS are better than the best-so-far solution from the IHA. A schematic view of the comparison of the minimum annual costs obtained by different algorithms is demonstrated in Figure 10. Notably, the proposed ISFS algorithm is more robust than the IHA due to the gain of smaller standard deviation and faster average CPU time. Moreover, after SC allocation, the voltage profiles at buses are significantly improved as shown in Figure 11. Finally, Figure 12 portrays the current change in lines before and after compensation. From Figure 12, it is realized that the current magnitude on most lines is mitigated because of reactive power injection.

5.2.2. Scenario 2: Modified Cost Objective Function. To deal with scenario 2, the obtained locations of switched SCs in scenario 1 are retained and the corresponding sizes of these switched SCs according to the load variations are determined by implementing the proposed ISFS algorithm. Considering scenario 2 in the 69-bus RDN, there are two switched capacitor locations at buses 20 and 61 yielded by the previous scenario. The simulation results of the on/off scheduling of these switched SCs with the 24-hour load variation taking into account achieved by the ISFS and SFS methods are presented 


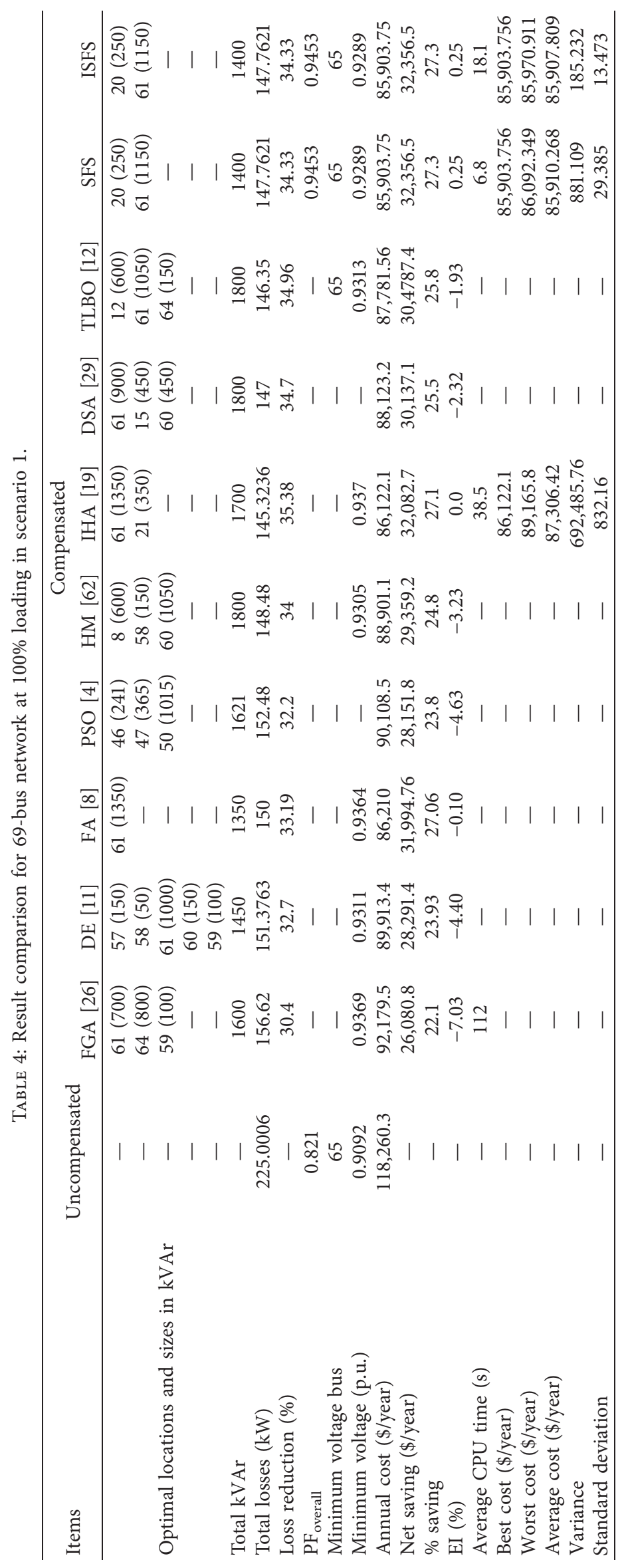




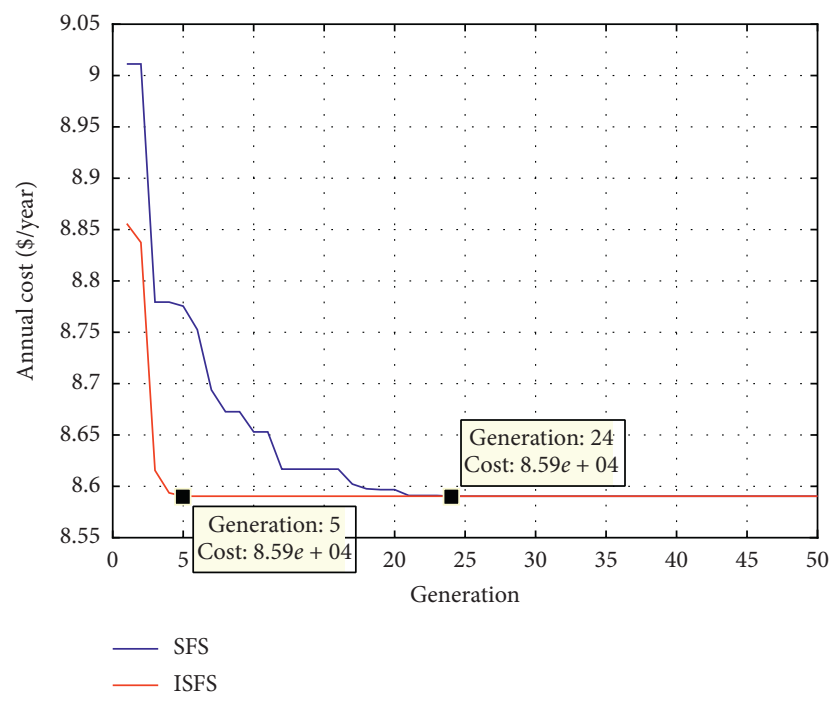

Figure 9: Convergence characteristics of annual cost for 69-bus network with 100\% loading in scenario 1.

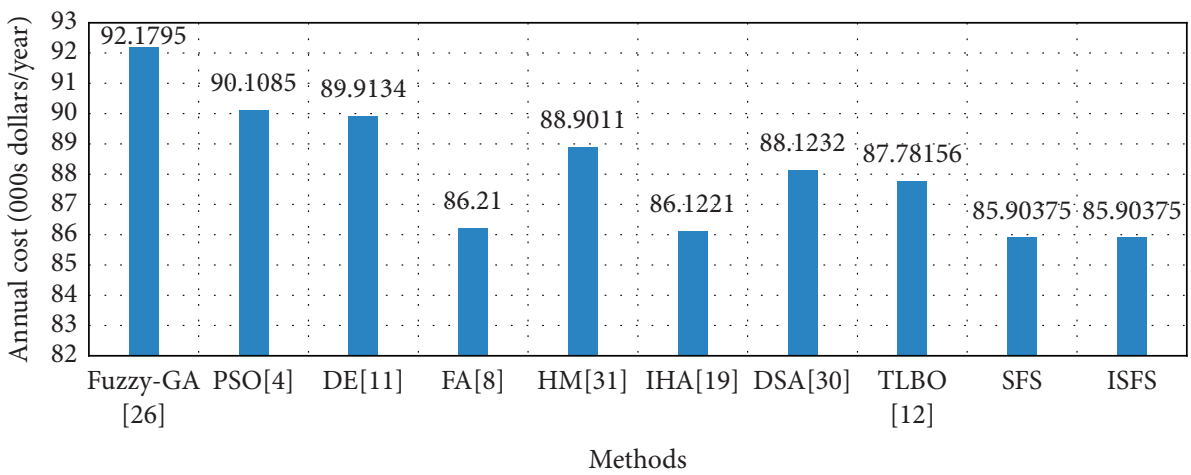

FIGURE 10: A schematic view of comparison of minimum annual costs obtained by different methods for 69-bus network.

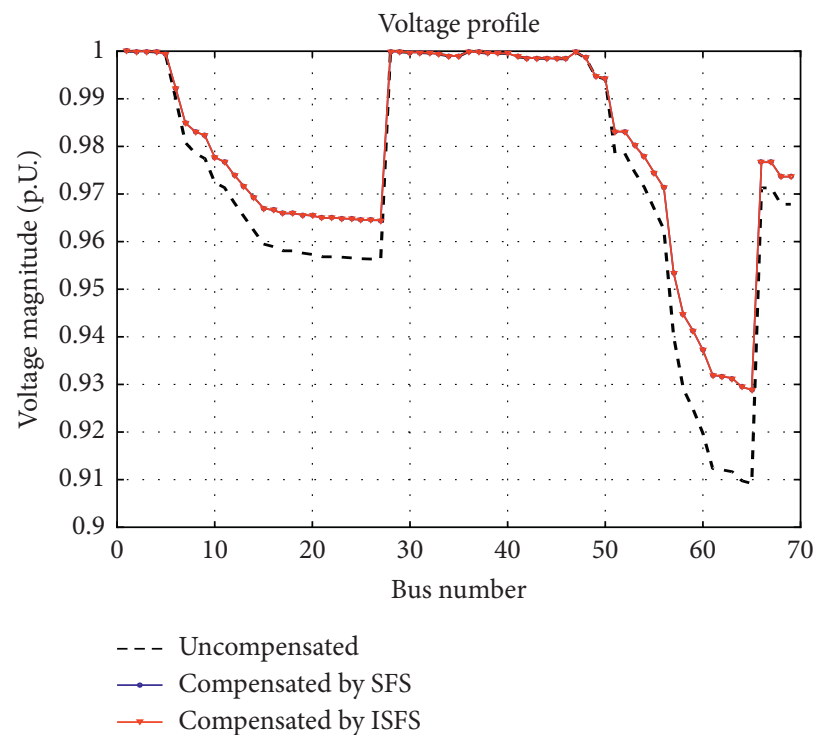

FIGURE 11: Bus voltage profile of 69-bus network with 100\% loading in scenario 1. 


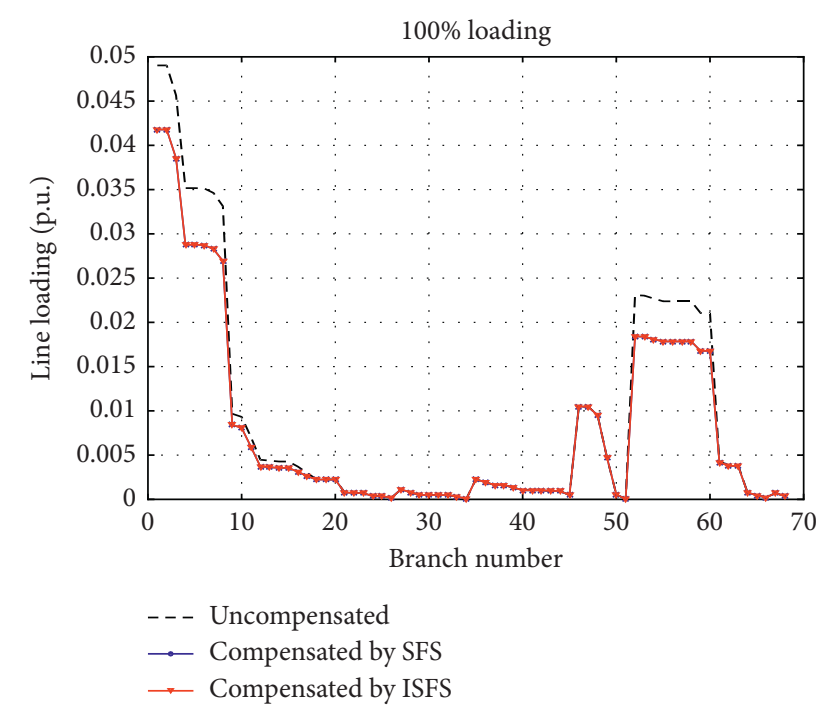

FIGURE 12: Line current of 69-bus network with $100 \%$ loading in scenario 1.

in Table 5. It is seen that the ISFS's optimum outcome is to install two fixed SCs at buses 20 and 61 with respective sizes of 50 and $500 \mathrm{kVAr}$ for compensating the reactive demand of the base loads. Also, the switched SCs at the same buses having respective sizes of 250 and $550 \mathrm{kVAr}$ with a step of 50 $\mathrm{kVAr}$ are connected to compensate for the variable reactive power demand of the load.

With the optimal compensation solution by the ISFS, the total annual cost of the network has been reduced from $\$ 164,792.27$ to $\$ 119,263.96$, leading to a saving percentage of $27.62 \%$, which is higher than a value of $27.16 \%$ from the SFS. In addition, Figure 13 portrays the convergence trajectories of the ISFS and SFS methods for test scenario 2. It is quite obvious from Figure 13 that the ISFS performs better than the SFS regarding search quality and convergence speed. Moreover, the comparison of network performances related to minimum bus voltage and line power loss before and after compensation with daily load variations is demonstrated in Figures 14 and 15, respectively. From these figures, it is clear that after optimal compensation, the overall performances of the network are significantly improved, especially in the case compensated by ISFS.

5.3. IEEE 119-Bus Network. The second test network is the standard IEEE large-scale RDN having 119 buses and 118 branches. This network supplies for active and reactive power demands of 22.709 MW and 17.041 MVAr, respectively, at the base values of $100 \mathrm{MVA}$ and $11 \mathrm{kV}$. It is observed that before compensation, the network active and reactive power losses are, respectively, $1298.091 \mathrm{~kW}$ and $978.736 \mathrm{kVAr}$. The load and line data of the test network are provided in [63].

5.3.1. Scenario 1: Traditional Cost Objective Function. For determination of the optimum number of SCs in the $100 \%$ load level, the simulation results relating to the impact of different SC numbers on the percentage in cost saving are represented in Figure 16. As observed from the figure, there are two trends for variations in the percentage of cost saving with the number of SCs increasing from 1 to 17. Specifically, an increase in the saving percentage is observed with the SC number from 1 to 13; however, when the number of SCs is changed from 14 to 17 , a downward trend in the saving percentage occurs. Obviously, the highest saving percentage is achieved at the number of 13 SCs. In other words, 13 SC placements result in the lowest total yearly cost as compared to the remaining number of SCs. Hence, the number of 13 SCs are chosen for the 119-bus network.

Table 6 provides the obtained results of the optimum number, locations, and sizes of SCs for different loading conditions by the proposed ISFS and the result comparisons with the other metaheuristic optimization algorithms. The relevant information on fixed and switched SCs is also given in Table 6. Based on the result comparisons, it can be seen that in all tested load levels, the ISFS acquires significantly lower annual cost objective values than other metaheuristic algorithms, showing the superior searching performance of ISFS. Moreover, the optimum parameters of SCs for the $100 \%$ loading level obtained by the ISFS and other algorithms can be found in Table 7. Specifically, the ISFS suggests candidate buses for 13 SC placements including $\{70,32,54$, $74,111,50,59,107,24,80,109,96,42\}$ with respective ratings $\{700,850,450,950,1350,1500,450,800,400,1200$, 300, 850, 550\} kVAr.

For further analysis on the performance of ISFS, the simulated results for the connection cases of the fixed and optimal SCs numbers to the 119-bus network, in the full load level, are tabulated and compared with the previously reported optimization algorithms such as ABC [15], APSO [5], CSA [16], HSA [9], IHA [19], FPA [18], MGABC [25], and the original SFS, as shown in Table 8. As realized from the table that in the test case of the fixed number of 9 SCs, the ISFS results in a significant improvement of network performance after SCs connection. Compared with other algorithms, the final solution by ISFS is appreciably better. It is worth mentioning that with the connection of the optimal SCs number, the performance of the network is even better improved as compared to the fixed number of SCs. Particularly, after compensation by the optimal number of 13 SCs with the help of ISFS, the network losses are reduced from $1298.09 \mathrm{~kW}$ to $812.5046 \mathrm{~kW}$, overall power factor is enhanced from 0.7998 to 0.9550 , minimum bus voltage is increased from 0.869 p.u. to 0.9076 p.u. and the total annual cost is mitigated from $\$ 682,276.104$ to $\$ 486,862$.4 corresponding to the saving percentage of $28.64 \%$, which is the highest among the compared results.

The comparison of the minimum total annual costs achieved by other solution methods is depicted in Figure 17 . In addition, the final solutions for the test cases obtained by both the ISFS and SFS involve positive EIs, proving that the solution quality yielded by the ISFS and SFS is better than that of IHA [19], which is related to the best solution reported so far for the network. Meanwhile, the remaining algorithms do not contribute to improving the solution to the test network because the negative EIs are obtained. Notably, the EIs of solutions by ISFS are higher than those by 
TABLE 5: On/off scheduling of switched SCs by ISFS and SFS for 69-bus network in scenario 2.

\begin{tabular}{|c|c|c|c|c|c|c|c|c|c|c|c|}
\hline \multirow[b]{2}{*}{ Hour } & \multirow{2}{*}{$\begin{array}{l}\text { Load } \\
\text { level }\end{array}$} & \multicolumn{2}{|c|}{ Compensated by SFS } & \multicolumn{2}{|c|}{ Compensated by ISFS } & \multirow[b]{2}{*}{ Hours } & \multirow{2}{*}{$\begin{array}{l}\text { Load } \\
\text { level }\end{array}$} & \multicolumn{2}{|c|}{ Compensated by SFS } & \multicolumn{2}{|c|}{ Compensated by ISFS } \\
\hline & & $\begin{array}{c}\mathrm{kVAr} \text {, bus } \\
\quad \# 20\end{array}$ & $\begin{array}{c}\mathrm{kVAr} \text {, bus } \\
\# 61\end{array}$ & $\begin{array}{c}\mathrm{kVAr} \text {, bus } \\
\# 20\end{array}$ & $\begin{array}{c}\mathrm{kVAr} \text {, bus } \\
\quad \# 61\end{array}$ & & & $\begin{array}{c}\mathrm{kVAr} \text {, bus } \\
\# 20\end{array}$ & $\begin{array}{c}\mathrm{kVAr} \text {, bus } \\
\quad \# 61\end{array}$ & $\begin{array}{c}\mathrm{kVAr} \text {, bus } \\
\quad \# 20\end{array}$ & $\begin{array}{c}\mathrm{kVAr} \text {, bus } \\
\# 61\end{array}$ \\
\hline 1 & 0.64 & 250 & 550 & 400 & 400 & 13 & 0.99 & 400 & 800 & 250 & 1000 \\
\hline 2 & 0.6 & 100 & 550 & 500 & 300 & 14 & 1 & 150 & 950 & 50 & 1000 \\
\hline 3 & 0.58 & 150 & 600 & 50 & 550 & 15 & 1 & 150 & 950 & 50 & 1000 \\
\hline 4 & 0.56 & 200 & 500 & 100 & 600 & 16 & 0.97 & 200 & 1050 & 500 & 600 \\
\hline 5 & 0.56 & 200 & 500 & 100 & 600 & 17 & 0.96 & 450 & 700 & 400 & 850 \\
\hline 6 & 0.58 & 150 & 600 & 50 & 550 & 18 & 0.96 & 450 & 700 & 400 & 850 \\
\hline 7 & 0.64 & 250 & 550 & 400 & 400 & 19 & 0.93 & 200 & 1050 & 150 & 1100 \\
\hline 8 & 0.76 & 350 & 600 & 300 & 600 & 20 & 0.92 & 300 & 850 & 200 & 1000 \\
\hline 9 & 0.87 & 450 & 600 & 200 & 950 & 21 & 0.92 & 300 & 850 & 200 & 1000 \\
\hline 10 & 0.95 & 300 & 700 & 500 & 550 & 22 & 0.93 & 200 & 1050 & 150 & 1100 \\
\hline 11 & 0.99 & 400 & 800 & 250 & 1000 & 23 & 0.87 & 450 & 600 & 200 & 950 \\
\hline 12 & 1 & 150 & 950 & 50 & 1000 & 24 & 0.72 & 250 & 500 & 350 & 550 \\
\hline \multirow{3}{*}{\multicolumn{3}{|c|}{ Annual cost (\$/year) }} & \multicolumn{3}{|c|}{ Uncompensated } & \multicolumn{2}{|c|}{$164,792.27$} & & \\
\hline & & & \multirow{2}{*}{\multicolumn{2}{|c|}{$\begin{array}{l}\text { Compensated by SFS } \\
\text { Compensated by ISFS }\end{array}$}} & & \multirow{2}{*}{\multicolumn{2}{|c|}{$\begin{array}{l}120,019.63 \\
119,263.96\end{array}$}} & & & \multirow{2}{*}{\multicolumn{2}{|c|}{$\begin{array}{l}27.16 \\
27.62\end{array}$}} \\
\hline & & & & & & & & \multicolumn{2}{|c|}{$\%$ saving } & & \\
\hline
\end{tabular}

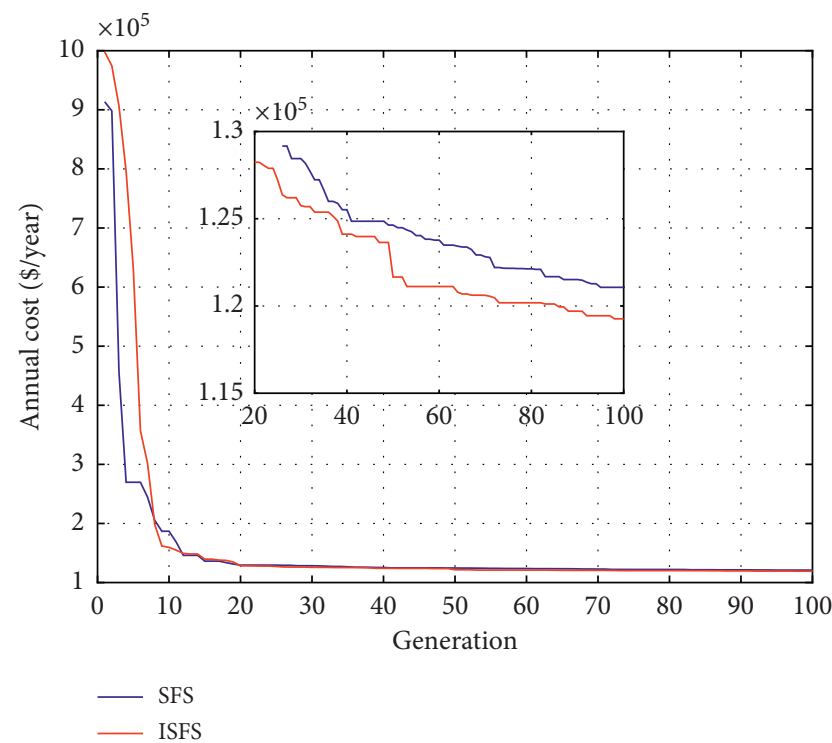

FIGURE 13: Convergence characteristics of annual cost for 69-bus network in scenario 2 .

SFS in both test cases, which means that the ISFS acquires the solutions with better quality. Moreover, the statistical results after 50 runs of the ISFS and SFS for the test cases comprising of the average cost, best cost, worst cost, variance, standard deviation, and average CPU time are presented and compared with those of ABC [15], CSA [16], and IHA [19] as shown in Table 8. In comparison with IHA [19] in the 9 SCs case, although the average execution time of both ISFS and SFS is longer, the best cost and standard deviation obtained by them are remarkably lower. Also, to achieve a desirable penetration of SCs, the ABC [15] and CSA [16] require longer average execution time than the ISFS and SFS. Furthermore, the convergence characteristics

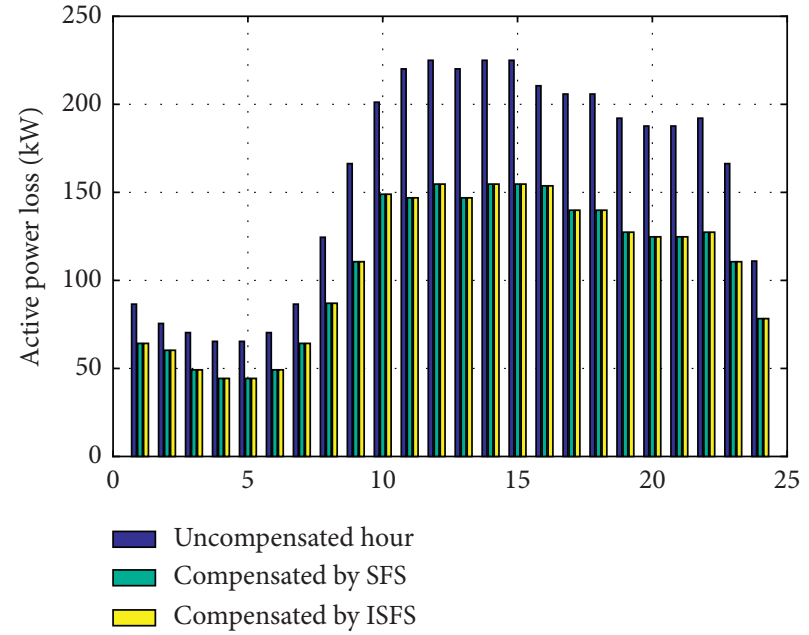

FIgURE 14: Power losses of 69-bus network within 24-hour interval before and after compensation in scenario 2 .

of the ISFS and SFS algorithms for the determination of locations and ratings of the optimal SCs number for the 119bus network are also depicted in Figure 18. From the figure, it is clear that the ISFS has effective search mechanisms that help to better explore promising search regions and to approach the optimal solution in the last iterations; meanwhile, the SFS's search mechanisms seem to be ineffective in this case because the obtained final solution can be further improved. Another noteworthy impact on network performance is that with the presence of the optimal SC number, the bus voltage profile and the current magnitude of lines in the network are significantly improved as shown in Figures 19 and 20, respectively.

5.3.2. Scenario 2: Modified Cost Objective Function. In this scenario, the optimal placements of the switched SCs found in 


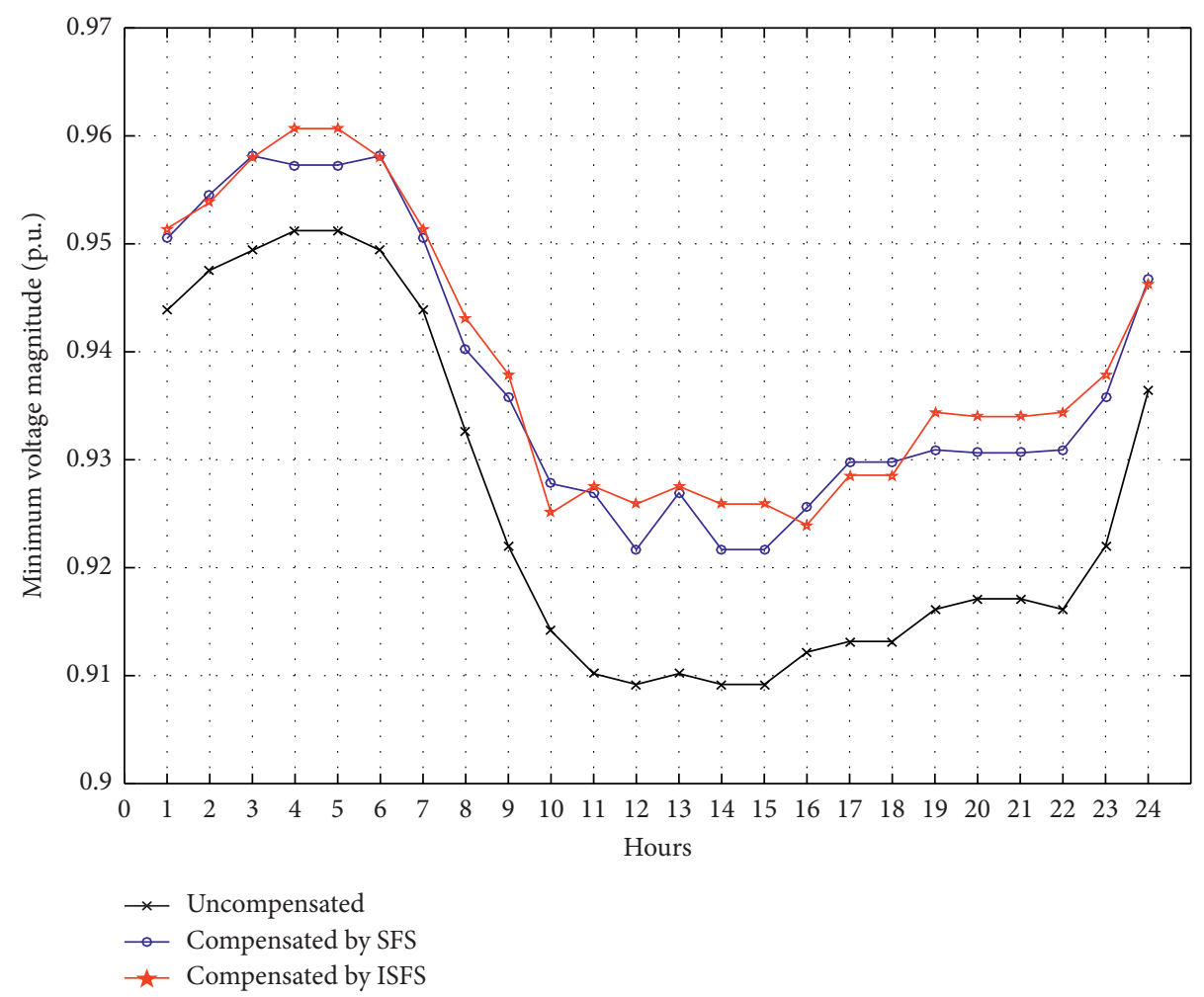

FIgURE 15: Minimum bus voltages of 69-bus network within 24-hour interval before and after compensation in scenario 2.

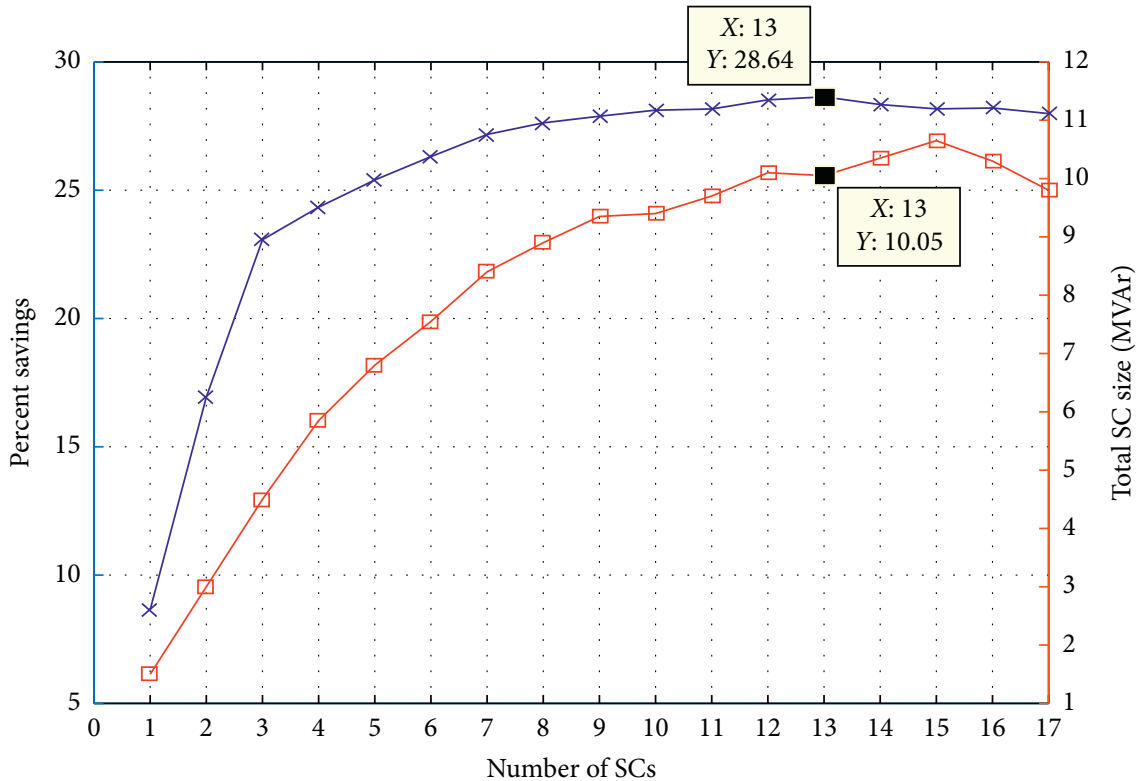

$\times 119$-bus percent savings

119-bus SC size

FIGURE 16: Effect of different numbers of SCs on performance of 119-bus network.

scenario 1 , namely, in buses $\{70,32,54,74,111,50,59,107,24$, $80,109,96,42\}$, are used for investigating the modified cost objective function. The on/off scheduling schemes of the switched SCs for the 119-bus network with practical 24-hour load pattern given in Tables 9 and 10 are optimized by using the SFS and ISFS algorithms, respectively. To meet the daily load variation, the ISFS offers a solution considering the installation of fixed SCs at buses $\{70,54,74,111,50,59,107$, $24,80,109,96,42\}$ with the corresponding sizes of $\{350,150$, $400,300,250,100,200,100,300,200,50,150\} \mathrm{kVAr}$ for base 
TABLE 6: Simulation results and comparison for 119-bus network at different loading conditions in scenario 1.

\begin{tabular}{|c|c|c|c|c|c|c|}
\hline \multirow{2}{*}{ Items } & \multirow{2}{*}{ Uncompensated } & \multicolumn{5}{|c|}{ Compensated } \\
\hline & & FPA [18] & IHA [19] & APSO [5] & MGABC [25] & Proposed ISFS \\
\hline \multicolumn{7}{|c|}{$50 \%$ load level } \\
\hline $\begin{array}{l}\text { Site and } \\
\text { installed } \\
\mathrm{kVAr}\end{array}$ & - & $\begin{array}{l}(40,1100) ;(70 \\
750) ;(89,500) ; \\
\quad(118,1000)\end{array}$ & $\begin{array}{l}(39,1200) ;(70 \\
900) ;(91,600) ; \\
(118,1000)\end{array}$ & $\begin{array}{l}(39,1100) ;(70 \\
350) ;(74,500) ; \\
(86,450) ;(118 \\
1000)\end{array}$ & $\begin{array}{c}(33,300) ;(35,750) ;(45 \\
300) ;(46,150) ;(49,900) \\
(54,450) ;(71,750) ;(76 \\
150) ;(86,750) ;(94,300) \\
(101,750) ;(110,600) ; \\
(111,450) ;(114,150) ; \\
(115,150)\end{array}$ & $\begin{array}{c}(74,650) ;(50,1000) ; \\
(80,350) ;(111,900) ; \\
(96,300)\end{array}$ \\
\hline Total kVAr & - & 3350 & 3700 & 3400 & 7200 & 3200 \\
\hline Losses in $\mathrm{kW}$ & 297.1485 & 209.0868 & 206.8402 & 271.9746 & 197.03 & 209.5486 \\
\hline $\begin{array}{l}\text { Loss } \\
\text { reduction } \\
(\%)\end{array}$ & - & 29.63 & 30.39 & 8.47 & 33.62 & 29.48 \\
\hline $\begin{array}{l}\text { Minimum } \\
\text { voltage (p.u.) }\end{array}$ & 0.9385 & - & 0.9552 & 0.9549 & 0.9574 & 0.9530 \\
\hline $\mathrm{PF}_{\text {overall }}$ & 0.7997 & 0.915 & 0.9188 & 0.9091 & 0.99 & 0.9036 \\
\hline $\begin{array}{l}\text { Annual cost } \\
\text { (\$/year) }\end{array}$ & $156,181.2$ & $129,126.02$ & $129,695.2$ & $163,049.89$ & $147,358.96$ & $129,238.76$ \\
\hline $\begin{array}{l}\text { Net saving } \\
\text { (\$/year) }\end{array}$ & - & $26,856.29$ & $26,287.1$ & $-6,868.62$ & $8,822.23$ & $26,942.50$ \\
\hline$\%$ saving & - & 17.32 & 16.95 & -4.39 & 5.64 & 17.25 \\
\hline \multicolumn{7}{|c|}{$75 \%$ load level } \\
\hline $\begin{array}{l}\text { Site and } \\
\text { installed } \\
\mathrm{kVAr}\end{array}$ & - & $\begin{array}{l}(40,1500) ;(70 \\
750) ;(74,600) ; \\
(89,1500) ;(118, \\
1000)\end{array}$ & $\begin{array}{l}(39,1500) ;(70 \\
900) ;(74,600) ; \\
(91,1500) ; \\
(118,1200)\end{array}$ & $\begin{array}{c}(32,900) ;(39, \\
1500) ;(70,600) ; \\
(74,750) ;(86, \\
700) ;(108,750) ; \\
(118,1100)\end{array}$ & $\begin{array}{c}(33,600) ;(35,1200) ;(45, \\
300) ;(46,150) ;(49 \\
1350) ;(54,750) ;(71 \\
1050) ;(76,300) ;(86 \\
1050) ;(94,450) ;(101 \\
1200) ;(110,900) ;(111 \\
600) ;(114,150) ;(115 \\
150)\end{array}$ & $\begin{array}{c}(24,300) ;(50,1150) ; \\
(74,600) ;(59,300) ; \\
(111,950) ;(109,700) ; \\
(42,400) ;(54,400) ; \\
(96,550) ;(80,750) ; \\
(70,600)\end{array}$ \\
\hline Total kVAr & - & 5350 & 5700 & 6300 & 10200 & 6700 \\
\hline $\begin{array}{l}\text { Losses in } \mathrm{kW} \\
\text { Loss }\end{array}$ & 697.32 & 488.83 & 473.1 & 551.9685 & 455.35 & 453.52 \\
\hline $\begin{array}{l}\text { Loss } \\
\text { reduction } \\
(\%)\end{array}$ & - & 29.89 & 32.15 & 20.84 & 34.62 & 34.96 \\
\hline $\begin{array}{l}\text { Minimum } \\
\text { voltage (p.u.) }\end{array}$ & 0.9048 & - & 0.92 & 0.932 & 0.9347 & 0.9308 \\
\hline $\mathrm{PF}_{\text {overall }}$ & 0.7997 & 0.914 & 0.9207 & 0.9308 & 0.988 & 0.9386 \\
\hline $\begin{array}{l}\text { Annual cost } \\
\text { (\$/year) }\end{array}$ & $366,515.4$ & $286,780.9$ & $280,261.4$ & $325,954.68$ & $299,631.96$ & $278,692.88$ \\
\hline $\begin{array}{l}\text { Net saving } \\
\text { (\$/year) }\end{array}$ & - & $78,994.7$ & $85,514.2$ & $40,560.72$ & $66,883.44$ & $87,822.51$ \\
\hline$\%$ saving & - & 21.75 & 23.53 & 11.06 & 18.24 & 23.96 \\
\hline \multicolumn{7}{|c|}{$100 \%$ load level } \\
\hline $\begin{array}{l}\text { Site and } \\
\text { installed } \\
\text { kVAr }\end{array}$ & - & 9 locations & 9 locations & 8 locations & 15 locations & 13 locations \\
\hline Total kVAr & & 9250 & 9800 & 9000 & 13500 & 10350 \\
\hline Losses in $\mathrm{kW}$ & 1298.09 & 853.1543 & 843.1459 & 858.89 & 833.46 & 812.5046 \\
\hline $\begin{array}{l}\text { Loss } \\
\text { reduction } \\
(\%)\end{array}$ & - & 34.27 & 35.04 & 33.83 & 35.72 & 37.40 \\
\hline $\begin{array}{l}\text { Minimum } \\
\text { voltage (p.u.) }\end{array}$ & 0.869 & - & 0.902 & 0.9063 & 0.9086 & 0.9076 \\
\hline $\mathrm{PF}_{\text {overall }}$ & 0.7998 & 0.9419 & 0.9488 & 0.92 & 0.988 & 0.9550 \\
\hline $\begin{array}{l}\text { Annual cost } \\
\text { (\$/year) }\end{array}$ & $682,276.104$ & $500,245.6$ & $497,737.5$ & $501,392.6$ & $514,866.5$ & $486,862.4$ \\
\hline $\begin{array}{l}\text { Net saving } \\
\text { (\$/year) }\end{array}$ & - & $180,064.7$ & $182,572.8$ & $180,883.5$ & $167,409.6$ & $195,413.6$ \\
\hline
\end{tabular}


TABLE 6: Continued.

\begin{tabular}{|c|c|c|c|c|c|c|}
\hline \multirow{2}{*}{ Items } & \multirow{2}{*}{ Uncompensated } & \multicolumn{5}{|c|}{ Compensated } \\
\hline & & FPA [18] & IHA [19] & APSO [5] & MGABC [25] & Proposed ISFS \\
\hline \multirow{3}{*}{$\begin{array}{l}\text { \% saving } \\
\text { Injected } \\
\text { kVAr by } \\
\text { proposed } \\
\text { ISFS }\end{array}$} & - & 26.67 & 27.04 & 26.51 & 24.53 & 28.64 \\
\hline & \multicolumn{6}{|c|}{ Fixed: $(50,1000) ;(74,600) ;(80,350) ;(96,300) ;(111,900)$} \\
\hline & \multicolumn{6}{|c|}{$\begin{array}{c}\text { Switched: }(24,400) ;(32,850) ;(42,550) ;(50,500) ;(54,450) ;(59,450) ;(70,700) ;(74,350) ;(80,850) ;(96,550) ;(107,800) \text {; } \\
(109,700) ;(111,450)\end{array}$} \\
\hline
\end{tabular}

TABLE 7: Optimal locations and sizes of SCs for 119-bus network at 100\% loading in scenario 1 by different methods.

\begin{tabular}{|c|c|c|c|}
\hline Method & $\begin{array}{l}\text { Number of } \\
\text { SCs }\end{array}$ & Locations and sizes in $\mathrm{kVAr}$ & $\begin{array}{l}\text { Total } \\
\text { kVAr }\end{array}$ \\
\hline $\mathrm{ABC}[15]$ & 11 & $\begin{array}{c}32 \text { (850); } 35 \text { (1050); } 40 \text { (1300); } 50 \text { (800); } 70 \text { (550); } 73(1300) ; 79 \text { (1200); } 105(700) ; 106(250) ; 109(800) ; \\
110 \text { (1200) }\end{array}$ & 10,000 \\
\hline CSA [16] & 8 & 32 (1500); 39 (1500); 40 (550); 70 (950); 74 (750); 86 (1050); 108 (1500); 118 (1200) & 9000 \\
\hline HSA [9] & 21 & $\begin{array}{c}79(714) ; 77(170) ; 76(192) ; 75(509) ; 74(272) ; 73(432) ; 72(386) ; 113(974) ; 56(375) ; 115(493) ; 54 \\
\text { (377); } 53 \text { (425); } 111 \text { (641); } 52(753) ; 112(793) ; 51(349) ; 71(513) ; 110(281) ; 50(165) ; 70(626) ; 49 \\
(488)\end{array}$ & 9928 \\
\hline APSO [5] & 8 & 32 (1500); 39 (1500); 40 (550); 70 (950); 74 (750); 86 (1050); 108 (1500); 118 (1200) & 9000 \\
\hline $\begin{array}{l}\text { MGABC } \\
{[25]}\end{array}$ & 15 & $\begin{array}{c}33(900) ; 35(1500) ; 45(450) ; 46(450) ; 49(1500) ; 54(1050) ; 71(1200) ; 76(450) ; 86(1350) ; 94(750) ; \\
101(1500) ; 110(1350) ; 111(750) ; 114(150) ; 115(150)\end{array}$ & 13,500 \\
\hline IHA [19] & 9 & 39 (1500); 43 (1000); 70 (1000); 74 (1000); 86 (900); 91 (1500); 107 (850); $109(850) ; 118(1200)$ & 9800 \\
\hline \multirow[t]{2}{*}{ FPA [18] } & 9 & 32 (1500); 40 (1500); 70 (850); 74 (1100); 89 (1500); 104 (500); 109 (900); $112(250) ; 118$ (1150) & 9250 \\
\hline & 9 & 42 (600); 50 (1500); 96 (900); 111 (1350); 80 (1250); 34 (1200); 74 (1450); 107 (1100); 58 (500) & 9850 \\
\hline \multirow[t]{2}{*}{ SFS } & 13 & $\begin{array}{c}111(1150) ; 54(450) ; 109(700) ; 42(600) ; 33(900) ; 80(1200) ; 74(900) ; 25(350) ; 97(850) ; 70(800) ; \\
106(800) ; 59(450) ; 50(1350)\end{array}$ & 10,500 \\
\hline & 9 & 50 (1500); 74 (1450); 107 (1000); 80 (1200); 96 (900); 58 (550); 42 (600); 35 (1000); 111 (1450) & 9650 \\
\hline ISFS & 13 & $\begin{array}{c}70 \text { (700); } 32 \text { (850); } 54 \text { (450); } 74 \text { (950); } 111(1350) ; 50(1500) ; 59(450) ; 107(800) ; 24(400) ; 80(1200) ; \\
109 \text { (300); } 96 \text { (850); 42(550) }\end{array}$ & 10,350 \\
\hline
\end{tabular}

load as well as the optimal locations and sizes of switched SCs of $\{70,32,54,74,111,50,59,107,24,80,109,96,42\}$ and $\{600$, $900,800,500,900,1200,550,750,550,700,850,650,400\}$ $\mathrm{kVAr}$ for variable load demand.

The compensation solution of the ISFS leads to an annual cost reduction from $\$ 950,263.63$ to $\$ 670,661.70$, which is slightly lower than a reduced annual cost of $\$ 671,523.90$ from the solution of the SFS. In addition, the convergence trajectories of the ISFS and SFS when dealing with this scenario are illustrated in Figure 21. Once again, the ISFS shows a faster convergence rate than the SFS in this scenario. Moreover, the improvements in the minimum bus voltage and the line power loss at a 24-hour interval can be observed in Figures 22 and 23, respectively.

5.4. Practical 152-Bus Network. To further evaluate the performance of ISFS, another practical large-scale RDN with 152 buses and 151 branches is examined. This network supplies a total power demand of $9.5893+j * 5.9429 \mathrm{MVA}$ at the base voltage of $20 \mathrm{kV}$. In the initial condition, the network involves a total power loss of $576.1616+j * 428.9281 \mathrm{kVA}$. The load and line data of the network are provided in [64].

5.4.1. Scenario 1: Traditional Objective Function. For this network, in the full load level, the effect of the different numbers of SCs on the cost saving percentage obtained by implementing the proposed ISFS algorithm is depicted in Figure 24. Observing this figure, it is clear that the penetration of three SCs leads to the highest percentage in cost saving among the penetration of the remaining number of SCs. In order words, the minimum total annual cost is achieved with the integration of three SC placements. Therefore, the number of three SCs is considered as the optimal number of SCs for the 152 -bus network in the $100 \%$ loading.

By applying the proposed ISFS, the optimum locations, and ratings of SCs for different loadings are given in Table 11. In addition, the parameters of fixed and switched SCs, losses, minimum bus voltage, overall power factor, total yearly cost, net saving, and percentage in saving are acquired. For the $100 \%$ loading, the ISFS assigns 3 SCs at buses 110,116 , and 147 with the same reactive power injection of $1500 \mathrm{kVAr}$.

For performance comparison analysis, the original SFS has been also applied for solving the problem in the full load case. The simulation results including network performance indexes and statistical analysis are tabulated in Table 12. It is obvious that the ISFS and SFS achieve the same final solution for this network. However, the ISFS is more robust than the SFS due to the gain of a lower standard deviation. The average execution time of the ISFS is longer than the SFS because of the extensive searching time of the integrated strategies as analyzed before. Importantly, the proposed ISFS requires fewer iterations than SFS to settle at the optimal solution, which is 67 iterations as compared to 86 iterations 


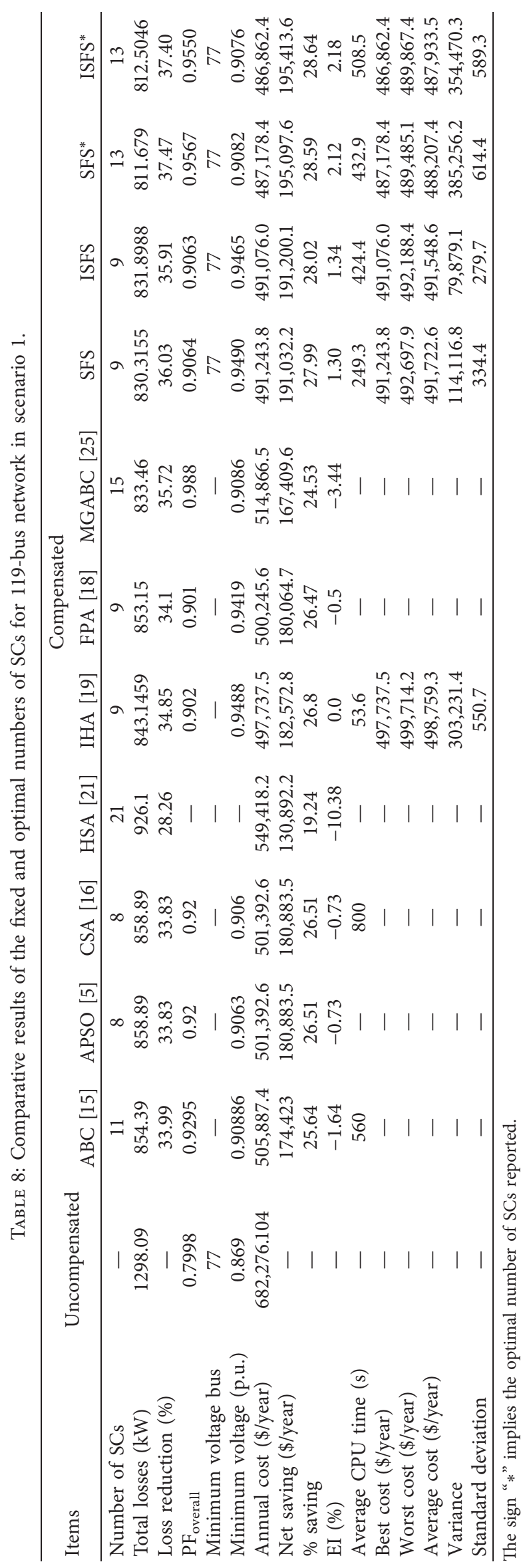




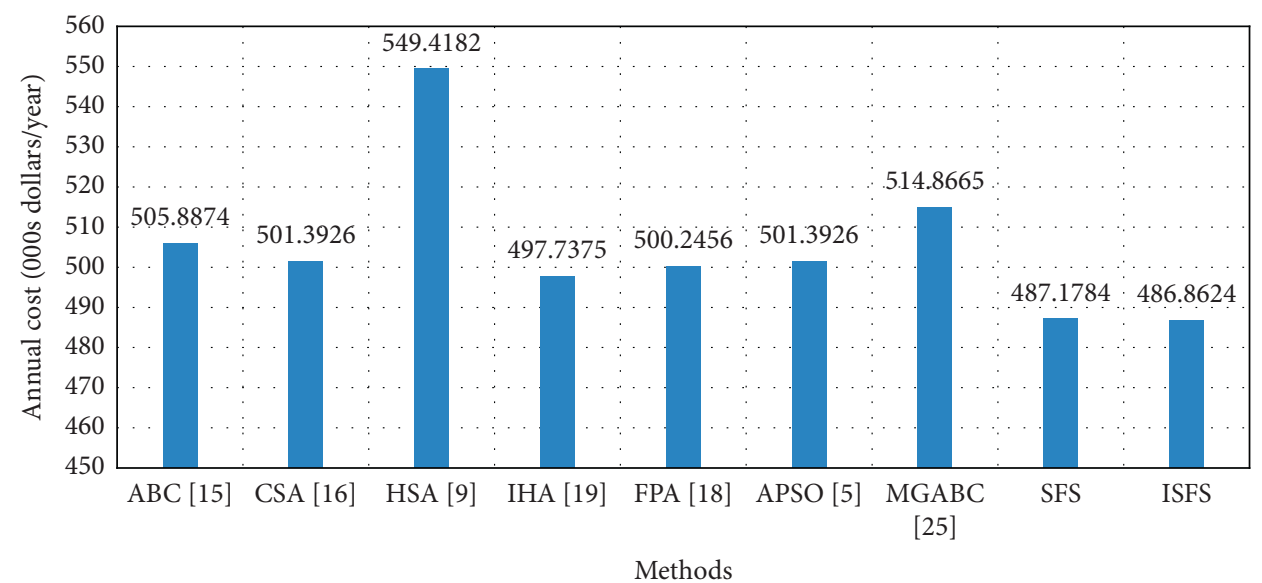

FIGURE 17: Comparison of minimum annual costs obtained by different methods for 119-bus network.

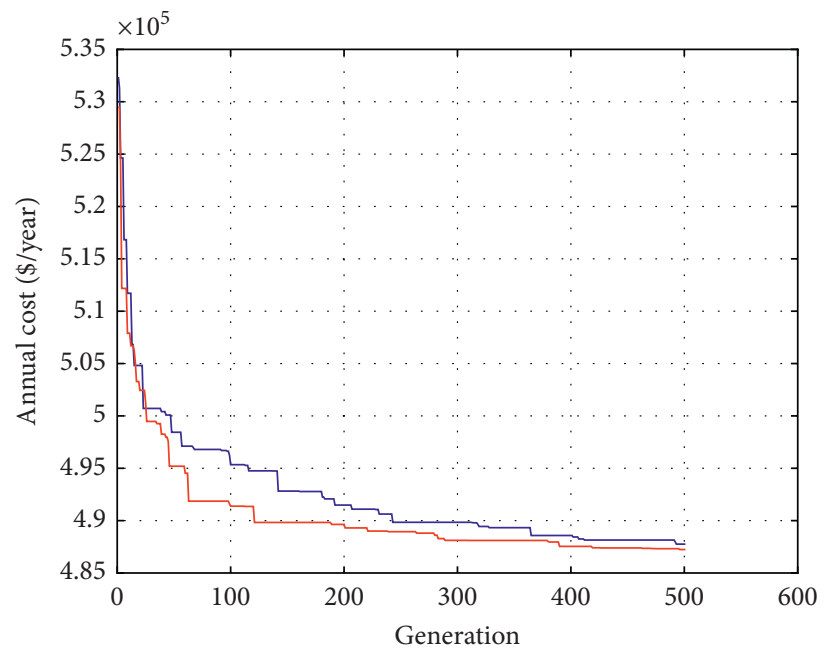

- SFS

Figure 18: Convergence characteristics of annual cost for 119-bus network with $100 \%$ loading in scenario 1 .

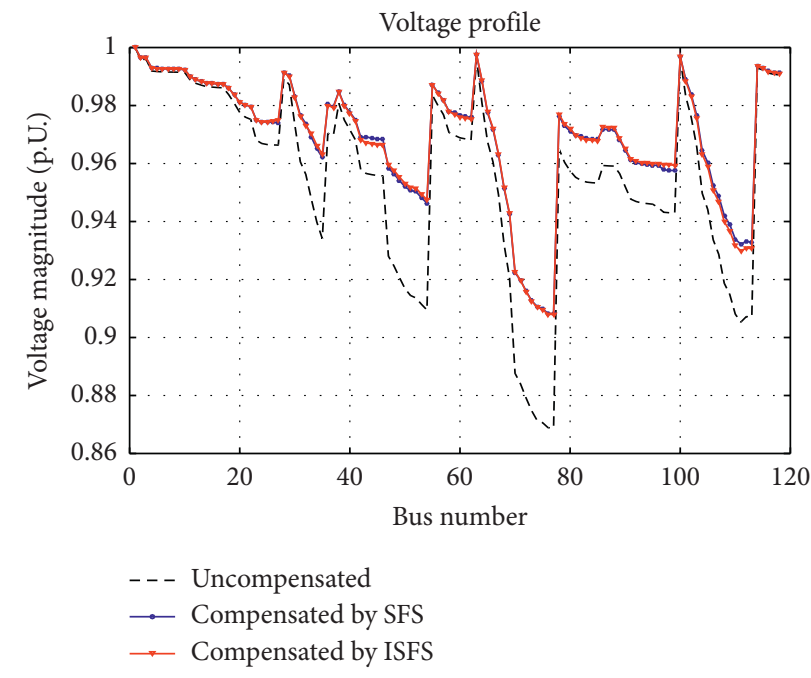

FIGURE 19: Bus voltage profile of 119-bus network with 100\% loading in scenario 1. 


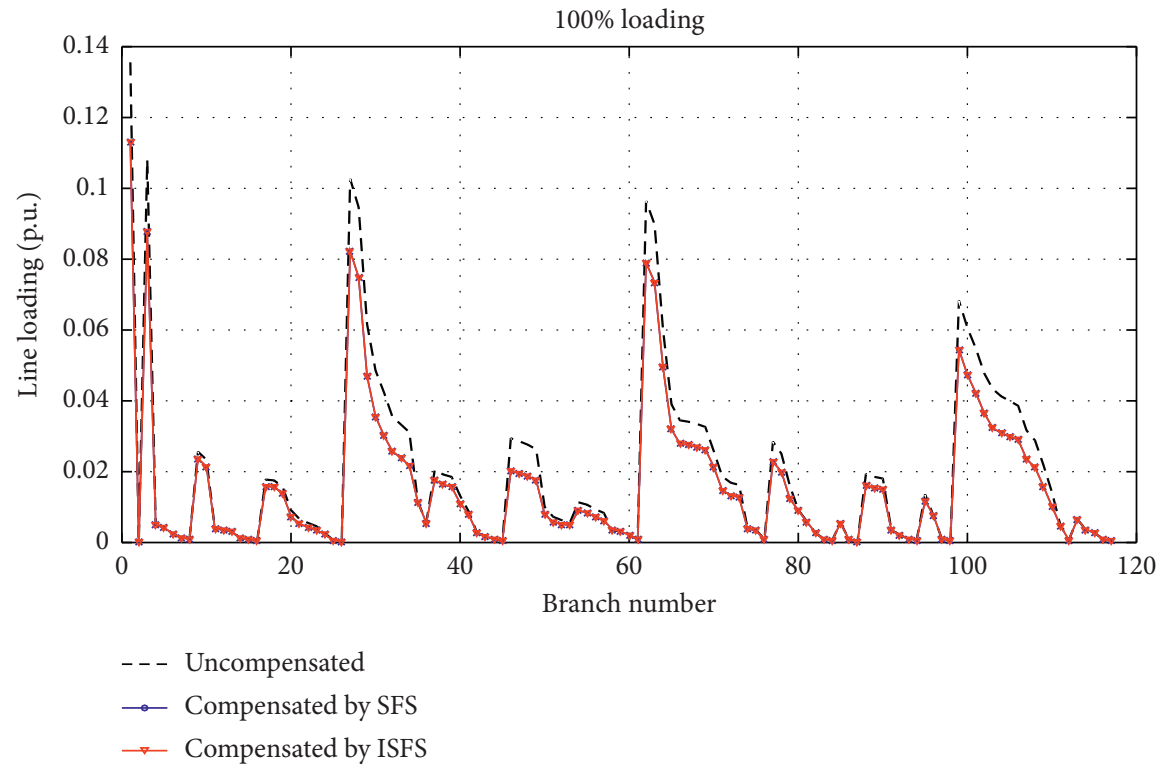

Figure 20: Line current of 119-bus network with 100\% loading in scenario 1 .

TABLE 9: On/off scheduling of switched SCs by SFS for 119-bus network in scenario 2.

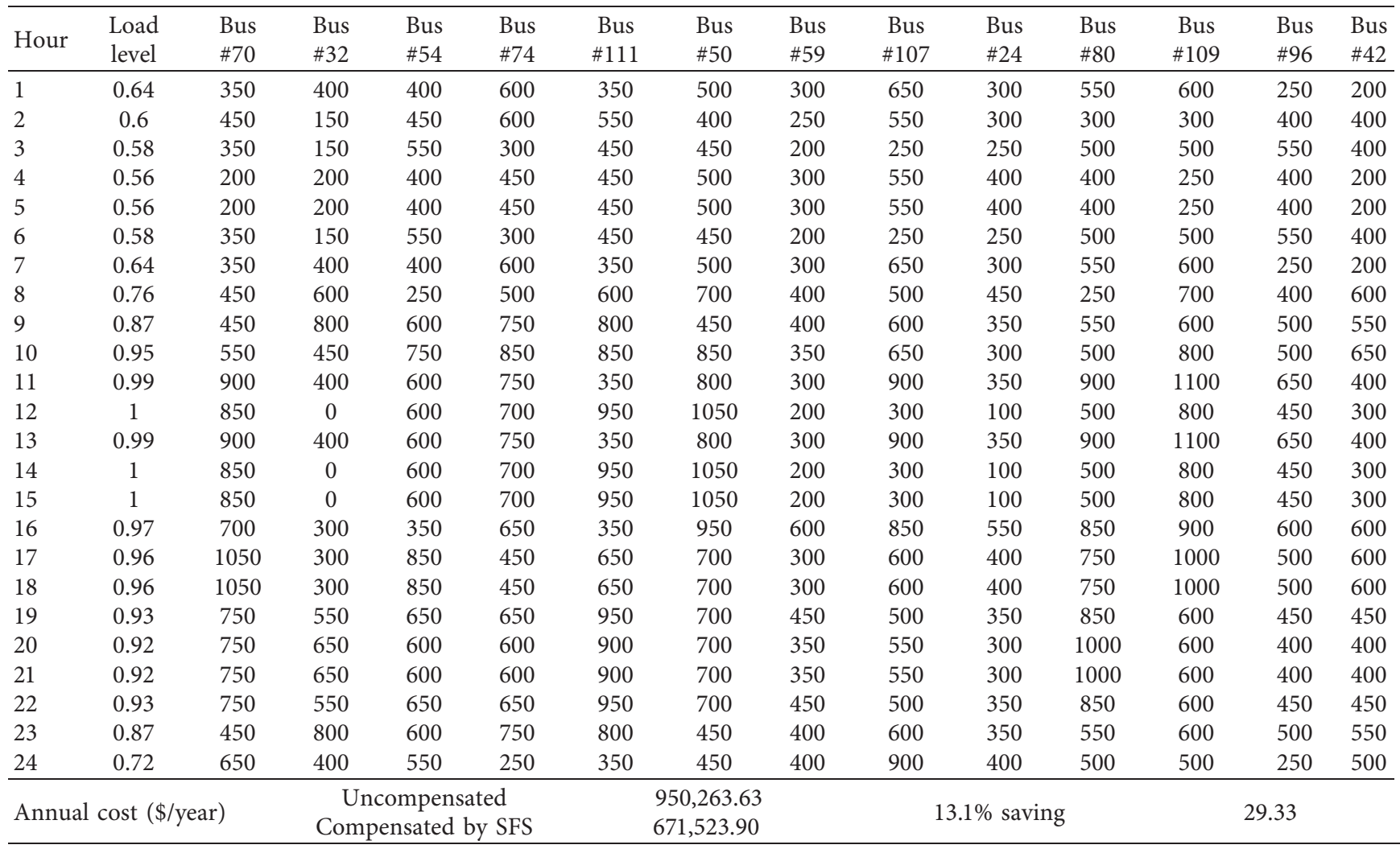

of SFS as shown in Figure 25. Moreover, the positive impacts of three SC placements on bus voltage and line current are shown in Figures 26 and 27, respectively.

5.4.2. Scenario 2: Modified Cost Objective Function. For solving this scenario, the switched SC locations obtained from scenario 1, namely, buses 110 and 116, are utilized. The results of the on/off scheduling plans of the switched SCs according to reactive power demand variations acquired by using the ISFS and SFS algorithms are disposed of in Table 13. It can be seen from the table that the proposed ISFS suggests the optimal locations and reactive powers of fixed SCs $\{(110,300) ;(116,250)\}$ for base load 
TABLE 10: On/off scheduling of switched SCs by ISFS for 119-bus network in scenario 2.

\begin{tabular}{|c|c|c|c|c|c|c|c|c|c|c|c|c|c|c|}
\hline Hour & $\begin{array}{l}\text { Load } \\
\text { level }\end{array}$ & $\begin{array}{l}\text { Bus } \\
\# 70\end{array}$ & $\begin{array}{l}\text { Bus } \\
\# 32\end{array}$ & $\begin{array}{l}\text { Bus } \\
\# 54\end{array}$ & $\begin{array}{l}\text { Bus } \\
\# 74\end{array}$ & $\begin{array}{c}\text { Bus } \\
\# 111\end{array}$ & $\begin{array}{l}\text { Bus } \\
\# 50\end{array}$ & $\begin{array}{l}\text { Bus } \\
\# 59\end{array}$ & $\begin{array}{l}\text { Bus } \\
\# 107\end{array}$ & $\begin{array}{l}\text { Bus } \\
\# 24\end{array}$ & $\begin{array}{l}\text { Bus } \\
\# 80\end{array}$ & $\begin{array}{c}\text { Bus } \\
\# 109 \\
\end{array}$ & $\begin{array}{l}\text { Bus } \\
\# 96 \\
\end{array}$ & $\begin{array}{l}\text { Bus } \\
\# 42 \\
\end{array}$ \\
\hline 1 & 0.64 & 500 & 450 & 650 & 550 & 400 & 250 & 300 & 350 & 300 & 350 & 700 & 300 & 350 \\
\hline 2 & 0.6 & 350 & 550 & 150 & 550 & 600 & 650 & 350 & 300 & 650 & 300 & 200 & 50 & 400 \\
\hline 3 & 0.58 & 350 & 400 & 200 & 500 & 500 & 550 & 200 & 450 & 300 & 450 & 350 & 400 & 250 \\
\hline 4 & 0.56 & 350 & 400 & 350 & 400 & 350 & 550 & 350 & 350 & 250 & 300 & 550 & 400 & 150 \\
\hline 5 & 0.56 & 350 & 400 & 350 & 400 & 350 & 550 & 350 & 350 & 250 & 300 & 550 & 400 & 150 \\
\hline 6 & 0.58 & 350 & 400 & 200 & 500 & 500 & 550 & 200 & 450 & 300 & 450 & 350 & 400 & 250 \\
\hline 7 & 0.64 & 500 & 450 & 650 & 550 & 400 & 250 & 300 & 350 & 300 & 350 & 700 & 300 & 350 \\
\hline 8 & 0.76 & 650 & 400 & 600 & 450 & 300 & 500 & 450 & 700 & 150 & 750 & 650 & 450 & 400 \\
\hline 9 & 0.87 & 900 & 450 & 800 & 600 & 600 & 550 & 400 & 300 & 250 & 500 & 1050 & 550 & 450 \\
\hline 10 & 0.95 & 800 & 600 & 850 & 550 & 550 & 550 & 400 & 750 & 450 & 1000 & 750 & 400 & 400 \\
\hline 11 & 0.99 & 800 & 450 & 850 & 900 & 1200 & 750 & 350 & 400 & 400 & 450 & 750 & 600 & 500 \\
\hline 12 & 1 & 750 & 0 & 450 & 700 & 1100 & 1450 & 100 & 300 & 100 & 500 & 600 & 400 & 300 \\
\hline 13 & 0.99 & 800 & 450 & 850 & 900 & 1200 & 750 & 350 & 400 & 400 & 450 & 750 & 600 & 500 \\
\hline 14 & 1 & 750 & 0 & 450 & 700 & 1100 & 1450 & 100 & 300 & 100 & 500 & 600 & 400 & 300 \\
\hline 15 & 1 & 750 & 0 & 450 & 700 & 1100 & 1450 & 100 & 300 & 100 & 500 & 600 & 400 & 300 \\
\hline 16 & 0.97 & 850 & 800 & 600 & 750 & 650 & 550 & 650 & 950 & 450 & 600 & 550 & 400 & 450 \\
\hline 17 & 0.96 & 800 & 900 & 800 & 500 & 1050 & 400 & 500 & 250 & 300 & 800 & 650 & 650 & 550 \\
\hline 18 & 0.96 & 800 & 900 & 800 & 500 & 1050 & 400 & 500 & 250 & 300 & 800 & 650 & 650 & 550 \\
\hline 19 & 0.93 & 950 & 450 & 500 & 500 & 750 & 1050 & 250 & 200 & 350 & 700 & 1000 & 700 & 500 \\
\hline 20 & 0.92 & 850 & 400 & 750 & 650 & 900 & 850 & 350 & 550 & 250 & 400 & 750 & 650 & 450 \\
\hline 21 & 0.92 & 850 & 400 & 750 & 650 & 900 & 850 & 350 & 550 & 250 & 400 & 750 & 650 & 450 \\
\hline 22 & 0.93 & 950 & 450 & 500 & 500 & 750 & 1050 & 250 & 200 & 350 & 700 & 1000 & 700 & 500 \\
\hline 23 & 0.87 & 900 & 450 & 800 & 600 & 600 & 550 & 400 & 300 & 250 & 500 & 1050 & 550 & 450 \\
\hline 24 & 0.72 & 550 & 350 & 950 & 500 & 700 & 300 & 450 & 550 & 300 & 600 & 400 & 300 & 150 \\
\hline \multicolumn{3}{|c|}{ Annual cost (\$/year) } & \multicolumn{3}{|c|}{$\begin{array}{c}\text { Uncompensated } \\
\text { Compensated by SFS }\end{array}$} & & 0,263 & & \multicolumn{3}{|c|}{$\%$ saving } & \multicolumn{3}{|c|}{29.42} \\
\hline
\end{tabular}

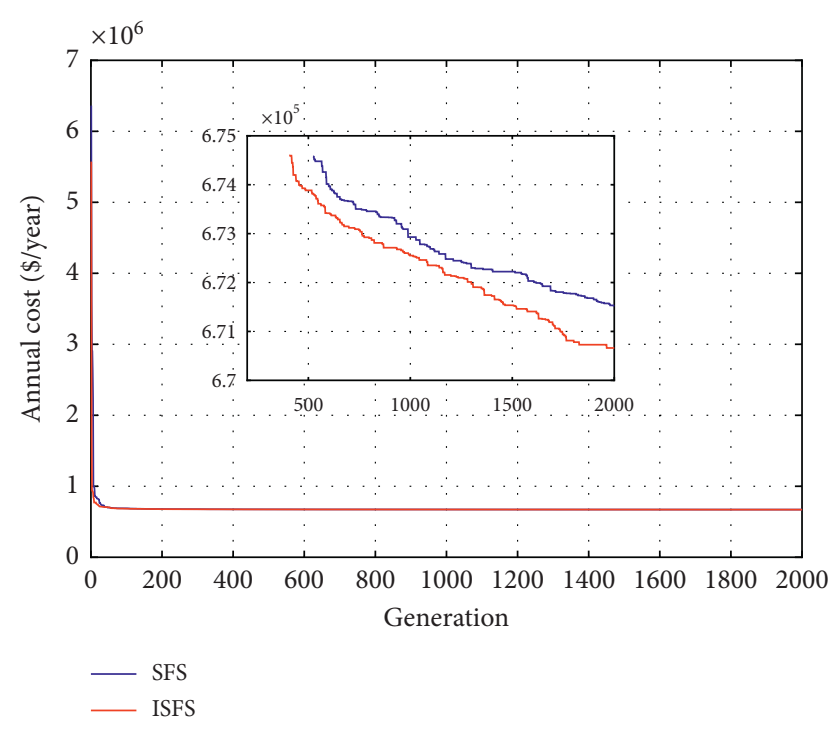

FIGURE 21: Convergence characteristics of annual cost for 119-bus network in scenario 2 .

compensation and the optimal parameters of switched SCs $\{(110,900) ;(116,1050)\}$ for compensating the variable load demands. After compensation with the ISFS, the total yearly cost is reduced to $\$ 331,586.05$ as compared to a value of $\$ 423,718.04$ in the uncompensated case. Moreover, the annual cost acquired by the ISFS is slightly more reduced than that obtained by the SFS, which is $\$ 331,586.05$ in

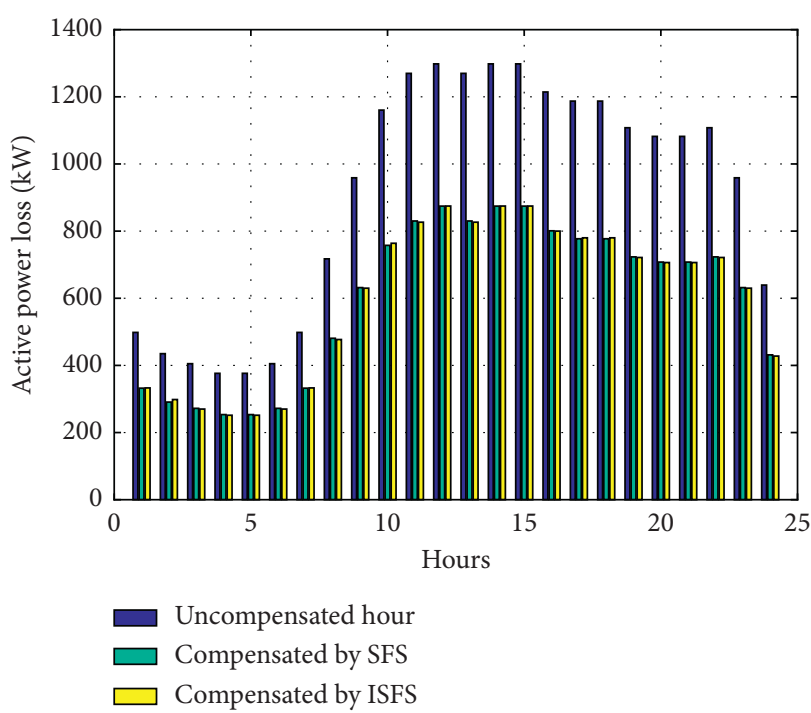

Figure 22: Power losses of 119-bus network within 24-hour interval before and after compensation in scenario 2 .

comparison with $\$ 331,586.65$. In addition, the proposed ISFS manifests superiority over the original SFS in terms of convergence speed for solving this scenario as shown in Figure 28. Finally, the positive changes related to the minimum bus voltage and the power losses in lines followed by the switching operation schemes from the ISFS and SFS can be seen in Figures 29 and 30, respectively. 


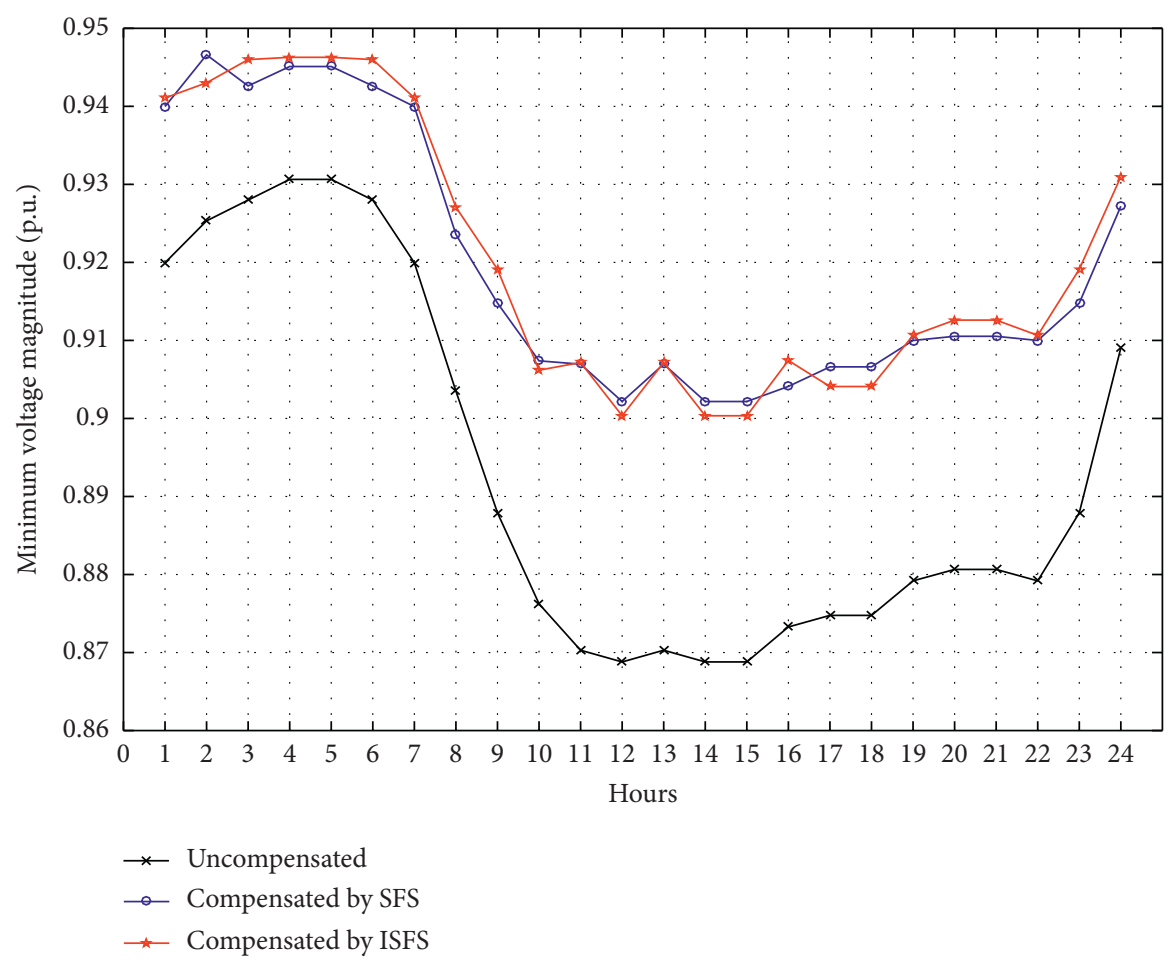

FIgURe 23: Minimum bus voltages of 119-bus network within 24-hour interval before and after compensation in scenario 2.

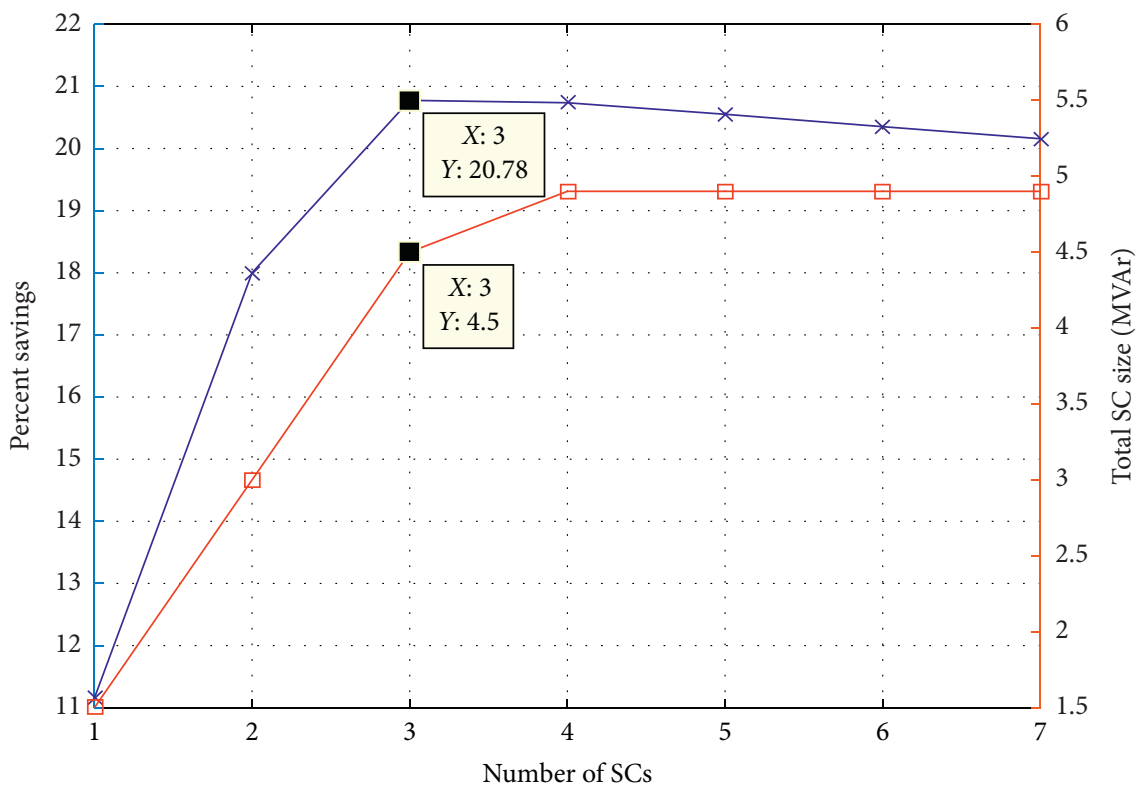

$\leftarrow$ 152-bus percent savings

$\square$ 152-bus SC size

Figure 24: Effect of different numbers of SCs on performance of 152-bus network. 
TABLE 11: Simulation results for 152-bus network at different loading conditions using proposed ISFS.

\begin{tabular}{|c|c|c|c|c|c|c|}
\hline \multirow{2}{*}{ Items } & \multicolumn{3}{|c|}{ Uncompensated in loading levels } & \multicolumn{3}{|c|}{ Compensated in loading levels } \\
\hline & $50 \%$ & $75 \%$ & $100 \%$ & $50 \%$ & $75 \%$ & $100 \%$ \\
\hline Site and installed kVAr & - & - & - & $(147,1500)$ & $\begin{array}{c}(110,1500) ;(147, \\
1500)\end{array}$ & $\begin{array}{c}(110,1500) ;(116,1500) ;(147, \\
1500)\end{array}$ \\
\hline Total kVAr & - & - & - & 1500 & 3000 & 4500 \\
\hline Losses in $\mathrm{kW}$ & 134.8582 & 313.3251 & 576.1617 & 104.7613 & 229.3269 & 410.1157 \\
\hline Loss reduction (\%) & - & - & - & 22.31 & 26.80 & 28.81 \\
\hline Minimum voltage (p.u.) & 0.9692 & 0.9531 & 0.9365 & 0.9746 & 0.964 & 0.9531 \\
\hline $\mathrm{PF}_{\text {overall }}$ & 0.8487 & 0.8480 & 0.8473 & 0.9534 & 0.9767 & 0.985 \\
\hline Annual cost (\$/year) & $70,881.46$ & $164,683.65$ & $302,830.56$ & $63,182.51$ & $136,774.21$ & $239,916.83$ \\
\hline Net saving (\$/year) & - & - & - & $7,698.95$ & $27,909.44$ & $62,913.73$ \\
\hline$\%$ saving & - & - & - & 10.86 & 16.94 & 20.77 \\
\hline Injected $\mathrm{kVAr}$ by proposed & \multicolumn{6}{|c|}{ Fixed: $(147,1500)$} \\
\hline ISFS & \multicolumn{6}{|c|}{ Switched: $(110,1500) ;(116,1500)$} \\
\hline
\end{tabular}

TABLE 12: Result comparison of ISFS and SFS for 119-bus network at $100 \%$ loading in scenario 1.

\begin{tabular}{lccc}
\hline Items & Uncompensated & Applied SFS & Compensated \\
& & $(110,1500) ;(116,1500) ;(147,1500)$ & $(110,1500) ;(116,1500) ;(147,1500)$ \\
Site and installed kVAr & - & 4500 & 4500 \\
Total kVAr & - & 410.1157 & 410.1157 \\
Total losses (kW) & 576.1617 & 28.81 & 28.81 \\
Loss reduction (\%) & - & 0.985 & 0.985 \\
PF overall & 0.8473 & 35 & 35 \\
Minimum voltage bus & 35 & 0.9531 & 0.9531 \\
Minimum voltage (p.u.) & 0.9365 & $239,916.83$ & $239,916.83$ \\
Annual cost (\$/year) & $302,830.56$ & $62,913.73$ & $62,913.73$ \\
Net saving (\$/year) & - & 20.77 & 20.77 \\
\% saving & - & 75.4 & 149.3 \\
Average CPU time (s) & - & $239,916.83$ & $239,916.83$ \\
Best cost (\$/year) & - & $239,924.65$ & $239,923.00$ \\
Worst cost (\$/year) & - & $239,917.98$ & $239,917.34$ \\
Average cost (\$/year) & - & 3.3989 & 1.600 \\
Variance & - & 1.8251 & 1.2523 \\
Standard deviation & - & & \\
\hline
\end{tabular}

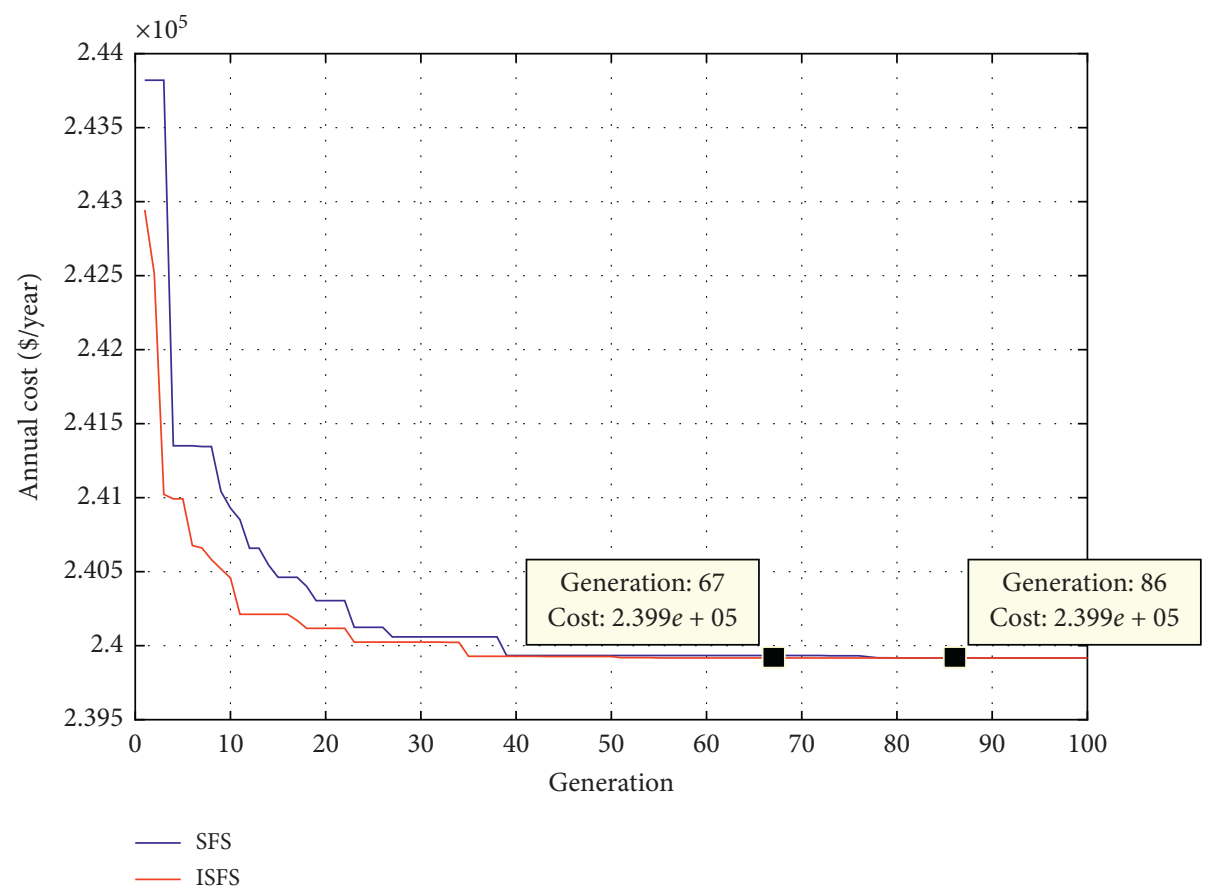

FIgURE 25: Convergence characteristics of annual cost for 152-bus network with $100 \%$ loading in scenario 1. 


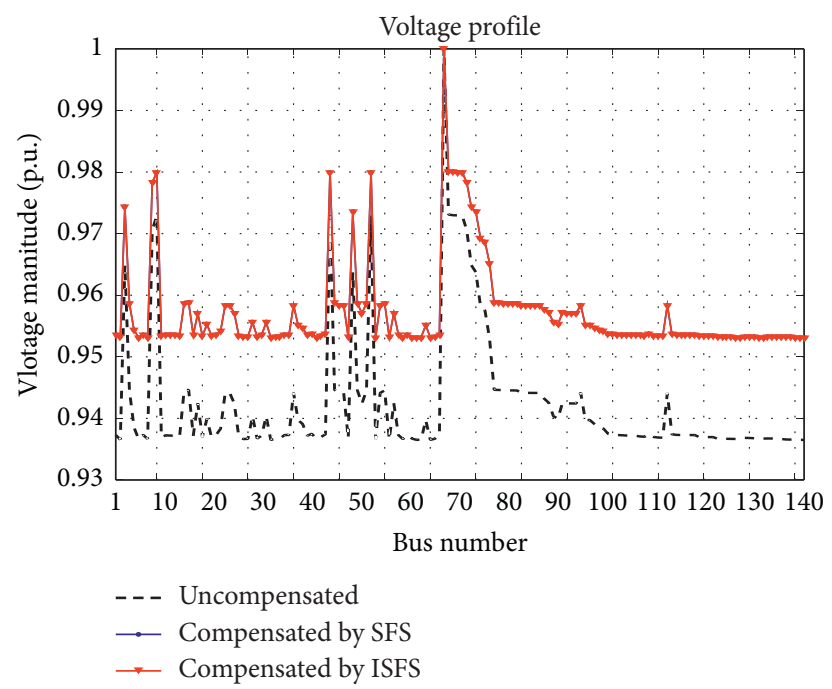

FIGURE 26: Bus voltage profile of 152-bus network with 100\% loading in scenario 1 after compensation.

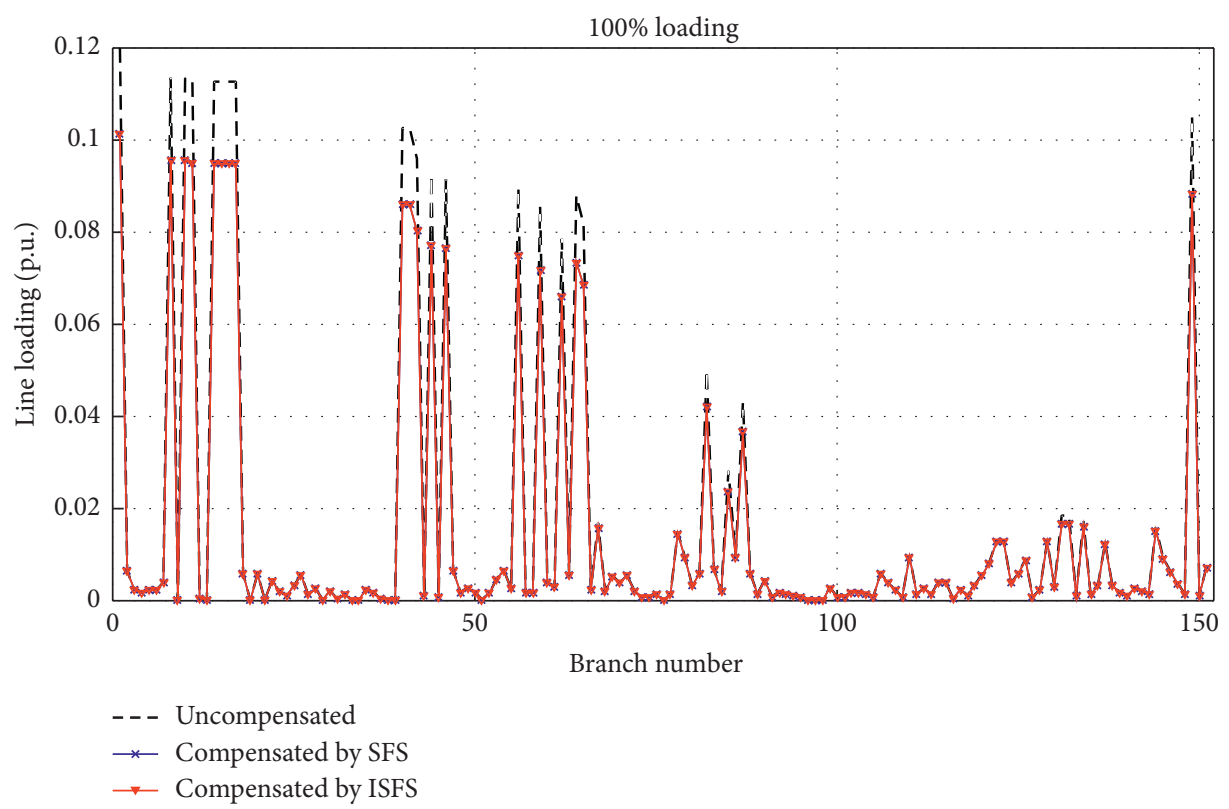

Figure 27: Line current of 152-bus network with 100\% loading in scenario 1 after compensation.

TABLE 13: On/off scheduling of switched SCs by ISFS and SFS for 152-bus network.

\begin{tabular}{|c|c|c|c|c|c|c|c|c|c|c|c|}
\hline \multirow[b]{2}{*}{ Hour } & \multirow[b]{2}{*}{ Load level } & \multicolumn{2}{|c|}{ Compensated by SFS } & \multicolumn{2}{|c|}{ Compensated by ISFS } & \multirow[b]{2}{*}{ Hours } & \multirow[b]{2}{*}{ Load level } & \multicolumn{2}{|c|}{ Compensated by SFS } & \multicolumn{2}{|c|}{ Compensated by ISFS } \\
\hline & & $\begin{array}{c}\mathrm{kVAr} \text {, bus } \\
\# 110\end{array}$ & $\begin{array}{c}\mathrm{kVAr} \text {, bus } \\
\quad \# 116\end{array}$ & $\begin{array}{c}\mathrm{kVAr} \text {, bus } \\
\quad \# 110\end{array}$ & $\begin{array}{c}\text { kVAr, bus } \\
\quad \# 116\end{array}$ & & & $\begin{array}{c}\text { kVAr, bus } \\
\# 110\end{array}$ & $\begin{array}{c}\mathrm{kVAr} \text {, bus } \\
\quad \# 116\end{array}$ & $\begin{array}{c}\mathrm{kVAr} \text {, bus } \\
\quad \# 110\end{array}$ & $\begin{array}{c}\text { kVAr, bus } \\
\quad \# 116\end{array}$ \\
\hline 1 & 0.64 & 550 & 600 & 900 & 250 & 13 & 0.99 & 1250 & 900 & 1000 & 1150 \\
\hline 2 & 0.6 & 450 & 550 & 350 & 650 & 14 & 1 & 1050 & 750 & 1000 & 800 \\
\hline 3 & 0.58 & 400 & 550 & 300 & 650 & 15 & 1 & 1050 & 750 & 1000 & 800 \\
\hline 4 & 0.56 & 450 & 450 & 550 & 350 & 16 & 0.97 & 1150 & 950 & 900 & 1200 \\
\hline 5 & 0.56 & 450 & 450 & 550 & 350 & 17 & 0.96 & 1200 & 900 & 1200 & 900 \\
\hline 6 & 0.58 & 400 & 550 & 300 & 650 & 18 & 0.96 & 1200 & 900 & 1200 & 900 \\
\hline 7 & 0.64 & 550 & 600 & 900 & 250 & 19 & 0.93 & 600 & 1400 & 1150 & 850 \\
\hline 8 & 0.76 & 400 & 1100 & 950 & 550 & 20 & 0.92 & 1000 & 950 & 650 & 1300 \\
\hline 9 & 0.87 & 1050 & 750 & 550 & 1250 & 21 & 0.92 & 1000 & 950 & 650 & 1300 \\
\hline 10 & 0.95 & 750 & 1300 & 1200 & 850 & 22 & 0.93 & 600 & 1400 & 1150 & 850 \\
\hline
\end{tabular}


TABLE 13: Continued.

\begin{tabular}{|c|c|c|c|c|c|c|c|c|c|c|c|}
\hline \multirow[b]{2}{*}{ Hour } & \multirow[b]{2}{*}{ Load level } & \multicolumn{2}{|c|}{ Compensated by SFS } & \multicolumn{2}{|c|}{ Compensated by ISFS } & \multirow[b]{2}{*}{ Hours } & \multirow[b]{2}{*}{ Load level } & \multicolumn{2}{|c|}{ Compensated by SFS } & \multicolumn{2}{|c|}{ Compensated by ISFS } \\
\hline & & $\begin{array}{c}\mathrm{kVAr} \text {, bus } \\
\# 110\end{array}$ & $\begin{array}{l}\text { kVAr, bus } \\
\quad \# 116\end{array}$ & $\begin{array}{c}\mathrm{kVAr} \text {, bus } \\
\quad \# 110\end{array}$ & $\begin{array}{c}\text { kVAr, bus } \\
\# 116\end{array}$ & & & $\begin{array}{c}\mathrm{kVAr} \text {, bus } \\
\quad \# 110\end{array}$ & $\begin{array}{c}\text { kVAr, bus } \\
\quad \# 116\end{array}$ & $\begin{array}{c}\text { kVAr, bus } \\
\# 110\end{array}$ & $\begin{array}{c}\mathrm{kVAr} \text {, bus } \\
\# 116\end{array}$ \\
\hline 11 & 0.99 & 1250 & 900 & 1000 & 1150 & 23 & 0.87 & 1050 & 750 & 550 & 1250 \\
\hline 12 & 1 & 1050 & 750 & 1000 & 800 & 24 & 0.72 & 400 & 950 & 350 & 1000 \\
\hline \multicolumn{3}{|c|}{ Annual cost (\$/year) } & $\begin{array}{r}\mathrm{U}_{1} \\
\text { Com } \\
\text { Com }\end{array}$ & $\begin{array}{l}\text { ncompensate } \\
\text { pensated by } \\
\text { pensated by }\end{array}$ & $\begin{array}{l}\text { ed } \\
\text { SFS } \\
\text { ISFS }\end{array}$ & & $\begin{array}{l}718.04 \\
, 586.65 \\
586.05\end{array}$ & \multicolumn{2}{|c|}{$\%$ saving } & $\begin{array}{l}21.74 \\
21.74\end{array}$ & $\begin{array}{l}.74 \\
.74\end{array}$ \\
\hline
\end{tabular}

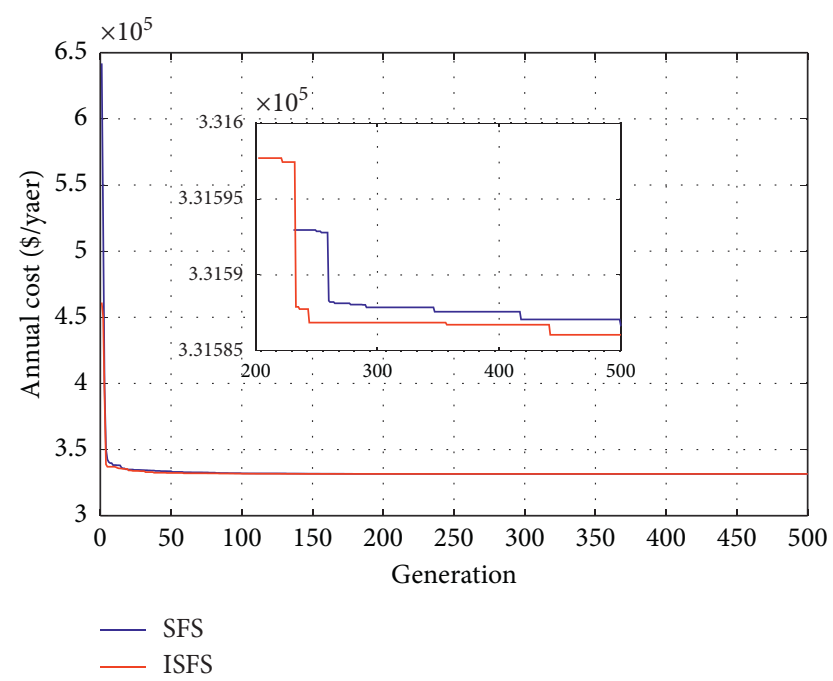

FIGURE 28: Convergence characteristics of annual cost for 152-bus network in scenario 2.

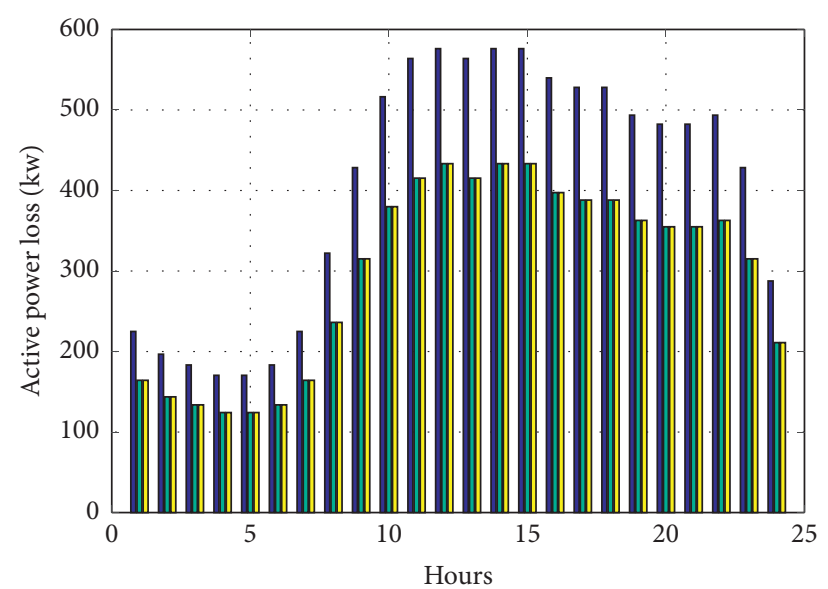

$\square$ Uncompensated

$\square$ Compensated by SFS

$\square$ Compensated by ISFS

FIGURE 29: Power losses of 152-bus network within 24-hour interval before and after compensation in scenario 2. 


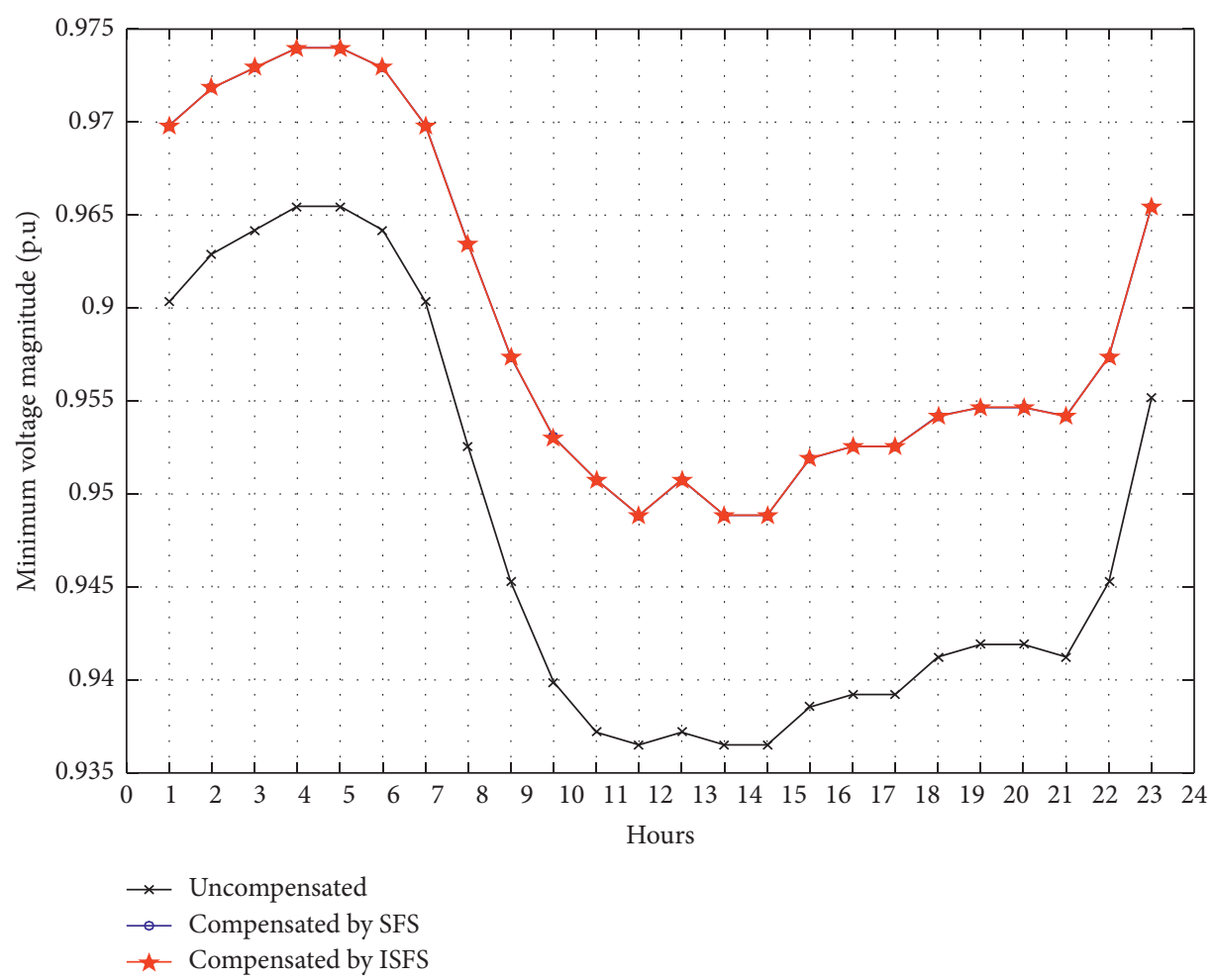

Figure 30: Minimum bus voltages of 152-bus network within 24-hour interval before and after compensation in scenario 2.

\section{Conclusion}

In this research, experiments are performed for optimum number, placement, and rating of SCs at different load levels to minimize the traditional objective function of total annual cost as well as for the on/off operation plans of switched SCs according to practical 24-hour load pattern to achieve the modified cost function minimization. The proposed ISFS algorithm is used as an effective optimization tool for extracting the optimal solution of the problem while fulfilling all the operational constraints. The computational performance of ISFS has been verified on three well-known RDNs including the 69, 119, and 152-bus networks. The experimented results reveal that the proposed ISFS contributes to remarkably improve the solution quality of the problem for the traditional cost function investigation as compared to other reported optimization algorithms. Notably, the proposed ISFS has been successfully applied for examining a complex scenario of capacitor switching operation with load variations. Moreover, the ISFS also outperforms the SFS regarding solution accuracy, convergence rate, and computational robustness in all the compared cases, especially in largescale networks with high computing complexity. Consequently, ISFS can be a very promising approach for coping with the OCP problem.

\section{Data Availability}

No data were used to support this study.

\section{Conflicts of Interest}

The authors declare that there are no conflicts of interest regarding the publication of this paper.

\section{Authors' Contributions}

Tri Nguyen Phuoc was responsible for software, validation, investigation, and original draft preparation. Thi Nguyen Anh contributed to review and editing. Dieu Vo Ngoc was responsible for conceptualization, methodology, review and editing, and supervision.

\section{Acknowledgments}

The authors acknowledge the support of time and facilities from Ho Chi Minh City University of Technology (HCMUT), VNU-HCM, for this study.

\section{References}

[1] R. S. Rao, S. V. L. Narasimham, and M. Ramalingaraju, "Optimal capacitor placement in a radial distribution system using plant growth simulation algorithm," International Journal of Electrical Power \& Energy Systems, vol. 33, no. 5, p. 1133, 2011.

[2] S. M. Kannan, P. Renuga, S. Kalyani, and E. Muthukumaran, "Optimal capacitor placement in radial distribution feeders using fuzzy-differential evolution for dynamic load 
condition," Journal of The Institution of Engineers (India): Series B, vol. 96, no. 4, pp. 363-370, 2015.

[3] H. N. Ng, M. M. A. Salama, and A. Y. Chikhani, "Classification of capacitor allocation techniques," IEEE Transactions on Power Delivery, vol. 15, no. 2, pp. 387-392, 2000.

[4] K. Prakash and M. Sydulu, "Particle swarm optimization based capacitor placement on radial distribution systems," in Proceedings of the 2007 Power Engineering Society General Meeting, pp. 1-5, Tampa, FL, USA, June 2007.

[5] A. A. El-Fergany and A. Y. Abdelaziz, "Efficient heuristicbased approach for multi-objective capacitor allocation in radial distribution networks," IET Generation, Transmission \& Distribution, vol. 8, no. 1, pp. 70-80, 2014.

[6] S. Sundararajan and A. Pahwa, "Optimal selection of capacitors for radial distribution systems using a genetic algorithm," IEEE Transactions on Power Systems, vol. 9, no. 3, pp. 1499-1507, 1994.

[7] Z. Hu, X. Wang, H. Chen, and G. A. Taylor, "Volt/VAr control in distribution systems using a time-interval based approach," IEE Proceedings-Generation, Transmission and Distribution, vol. 150, no. 5, pp. 548-554, 2003.

[8] P. Das and S. Banerjee, "Optimal sizing and placement of capacitor in A radial distribution system using loss sensitivity factor And firefly algorithm," International Journal of Engineering and Computer Science, vol. 3, no. 4, 2014.

[9] K. Muthukumar, S. Jayalalitha, M. Ramasamy, and C. Haricharan, "Optimal shunt capacitor allocation and sizing using harmony search algorithm for power loss minimization in radial distribution networks," International Journal of Development Research, vol. 4, no. 3, pp. 537-545, 2014.

[10] Y. Huang, H. Yang, and C. Huang, "Solving the capacitor placement problem in a radial distribution system using Tabu search approach," IEEE Transactions on Power Systems, vol. 11, no. 4, pp. 1868-1873, 1996.

[11] A. A. El-Fergany, "Optimal capacitor allocations using evolutionary algorithms," IET Generation, Transmission \& Distribution, vol. 7, no. 6, pp. 593-601, 2013.

[12] S. Sultana and P. K. Roy, "Optimal capacitor placement in radial distribution systems using teaching learning based optimization," International Journal of Electrical Power \& Energy Systems, vol. 54, pp. 387-398, 2014.

[13] S. M. Tabatabaei and B. Vahidi, "Bacterial foraging solution based fuzzy logic decision for optimal capacitor allocation in radial distribution system," Electric Power Systems Research, vol. 81, no. 4, pp. 1045-1050, 2011.

[14] Y. Shuaib, M. Kalavathi, and C. Asir, "Optimal capacitor placement in radial distribution system using gravitational search algorithm," International Journal of Electrical Power \& Energy Systems, vol. 64, pp. 384-397, 2015.

[15] A. A. El-Fergany and A. Y. Abdelaziz, "Artificial bee colony algorithm to allocate fixed and switched static shunt capacitors in radial distribution networks," Electric Power Components and Systems, vol. 42, no. 5, pp. 427-438, 2014.

[16] A. A. El-Fergany and A. Y. Abdelaziz, "Capacitor allocations in radial distribution networks using cuckoo search algorithm," IET Generation, Transmission \& Distribution, vol. 8, no. 2, pp. 223-232, 2014.

[17] A. A. Abou El-Ela, M. T. Mouwafi, A.-M. Kinawy, and R. A. El-Sehiemy, "Optimal capacitor placement in distribution systems for power loss reduction and voltage profile improvement," IET Generation, Transmission \& Distribution, vol. 10, no. 5, pp. 1209-1221, 2016.

[18] A. Y. Abdelaziz, E. S. Ali, and S. M. Abd Elazim, "Flower pollination algorithm for optimal capacitor placement and sizing in distribution systems," Electric Power Components and Systems, vol. 44, no. 5, pp. 544-555, 2016.

[19] E. S. Ali, S. M. Abd Elazim, and A. Y. Abdelaziz, "Improved harmony algorithm and power loss index for optimal locations and sizing of capacitors in radial distribution systems," International Journal of Electrical Power \& Energy Systems, vol. 80, pp. 252-263, 2016.

[20] A. Sharma, H. Sharma, A. Bhargava, N. Sharma, and J. C. Bansal, "Optimal placement and sizing of capacitor using Limaçon inspired spider monkey optimization algorithm," Memetic Computing, vol. 9, no. 4, pp. 311-331, 2017.

[21] M. Dehghani, Z. Montazeri, and O. P. Malik, "Optimal sizing and placement of capacitor banks and distributed generation in distribution systems using spring search algorithm," International Journal of Emerging Electric Power Systems, vol. 21, no. 1, 2020.

[22] A. M. Elsayed, M. M. Mishref, and S. M. Farrag, "Optimal allocation and control of fixed and switched capacitor banks on distribution systems using grasshopper optimisation algorithm with power loss sensitivity and rough set theory," IET Generation, Transmission \& Distribution, vol. 13, no. 17, pp. 3863-3878, 2019.

[23] I. Pérez Abril, "Capacitor placement by variables' inclusion and interchange improved algorithm," International Transactions on Electrical Energy Systems, vol. 30, no. 6, Article ID e12377, 2020.

[24] M. Montazeri and A. Askarzadeh, "Capacitor placement in radial distribution networks based on identification of high potential busses," International Transactions on Electrical Energy Systems, vol. 29, no. 3, Article ID e2754, 2019.

[25] M. Dixit, P. Kundu, and H. R. Jariwala, "Optimal integration of shunt capacitor banks in distribution networks for assessment of techno-economic asset," Computers \& Electrical Engineering, vol. 71, pp. 331-345, 2018.

[26] D. Das, "Optimal placement of capacitors in radial distribution system using a Fuzzy-GA method," International Journal of Electrical Power \& Energy Systems, vol. 30, no. 6-7, pp. 361-367, 2008.

[27] A. Abul'Wafa, "Optimal capacitor placement for enhancing voltage stability in distribution systems using analytical algorithm and fuzzy-real coded GA," International Journal of Electrical Power \& Energy Systems, vol. 55, pp. 246-252, 2014.

[28] R. Liang and Y. Wang, "Fuzzy-based reactive power and voltage control in a distribution system," IEEE Transactions on Power Delivery, vol. 18, no. 2, pp. 610-618, 2001.

[29] M. Rajua, K. Murthy, and K. Ravindra, "Direct search algorithm for capacitive compensation in radial distribution systems," International Journal of Electrical Power \& Energy Systems, vol. 42, no. 1, pp. 24-30, 2012.

[30] L. Ruey-Hsun and C. Chen-Kuo, "Dispatch of main transformer ULTC and capacitors in a distribution system," IEEE Transactions on Power Delivery, vol. 16, no. 4, pp. 625-630, 2001.

[31] A. Abul'Wafa, "Optimal capacitor allocation in radial distribution systems for loss reduction: a two stage method," Electric Power Systems Research, vol. 95, pp. 147-168, 2013.

[32] T. Monsef, N. Mohammed, E. Ramadan et al., "A review of volt/var control techniques in passive and active power distribution networks," in Proceedings of the 2016 4th IEEE International Conference on Smart Energy Grid Engineering, pp. 57-63, Oshawa, ON, Canada, August 2016.

[33] A. A. Abdelsalam and H. S. Mansour, "Optimal allocation and hourly scheduling of capacitor banks using sine cosine algorithm for maximizing technical and economic benefits," 
Electric Power Components and Systems, vol. 47, no. 11-12, pp. 1025-1039, 2019.

[34] H. Salimi, "Stochastic fractal search: a powerful metaheuristic algorithm," Knowledge-Based Systems, vol. 75, pp. 1-18, 2015.

[35] S. Rahnamayan, H. R. Tizhoosh, and M. M. A. Salama, "Quasi-oppositional differential evolution," in Proceedings of the 2007 IEEE Congress on Evolutionary Computation, pp. 2229-2236, Singapore, September 2007.

[36] C. K. Shiva and V. Mukherjee, "A novel quasi-oppositional harmony search algorithm for automatic generation control of power system," Applied Soft Computing, vol. 35, pp. 749$765,2015$.

[37] S. Sultana and P. K. Roy, "Multi-objective quasi-oppositional teaching learning based optimization for optimal location of distributed generator in radial distribution systems," International Journal of Electrical Power \& Energy Systems, vol. 63, pp. 534-545, 2014.

[38] D. Guha, P. K. Roy, and S. Banerjee, "Load frequency control of large scale power system using quasi-oppositional grey wolf optimization algorithm," Engineering Science and Technology, an International Journal, vol. 19, no. 4, pp. 1693-1713, 2016.

[39] S. Sharma, S. Bhattacharjee, and A. Bhattacharya, "Quasioppositional swine influenza model based optimization with quarantine for optimal allocation of DG in radial distribution network," International Journal of Electrical Power \& Energy Systems, vol. 74, pp. 348-373, 2016.

[40] E. Çelik, "A powerful variant of symbiotic organisms search algorithm for global optimization," Engineering Applications of Artificial Intelligence, vol. 87, Article ID 103294, 2020.

[41] S. Saha and V. Mukherjee, "A novel quasi-oppositional chaotic antlion optimizer for global optimization," Applied Intelligence, vol. 48, no. 9, pp. 2628-2660, 2018.

[42] D. Jia, G. Zheng, and M. Khurram Khan, "An effective memetic differential evolution algorithm based on chaotic local search," Information Sciences, vol. 181, no. 15, pp. 3175-3187, 2011.

[43] Y. He, Q. Xu, S. Yang, A. Han, and L. Yang, "A novel chaotic differential evolution algorithm for short-term cascaded hydroelectric system scheduling," International Journal of Electrical Power \& Energy Systems, vol. 61, pp. 455-462, 2014.

[44] J. Zhang, S. Lin, and W. Qiu, "A modified chaotic differential evolution algorithm for short-term optimal hydrothermal scheduling," International Journal of Electrical Power \& Energy Systems, vol. 65, pp. 159-168, 2015.

[45] Q.-K. Pan, L. Wang, and L. Gao, "A chaotic harmony search algorithm for the flow shop scheduling problem with limited buffers," Applied Soft Computing, vol. 11, no. 8, pp. 5270-5280, 2011.

[46] L.-Y. Chuang, C.-J. Hsiao, and C.-H. Yang, "Chaotic particle swarm optimization for data clustering," Expert Systems with Applications, vol. 38, no. 12, pp. 14555-14563, 2011.

[47] X. Xia, "Particle swarm optimization method based on chaotic local search and Roulette wheel mechanism," Physics Procedia, vol. 24, pp. 269-275, 2012.

[48] O. E. Turgut, "Hybrid chaotic quantum behaved particle swarm optimization algorithm for thermal design of plate fin heat exchangers," Applied Mathematical Modelling, vol. 40, no. 1, pp. 50-69, 2016.

[49] K. K. Bharti and P. K. Singh, "Chaotic gradient artificial bee colony for text clustering," Soft Computing, vol. 20, no. 3, pp. 1113-1126, 2016.

[50] X. He, Y. Rao, and J. Huang, "A novel algorithm for economic load dispatch of power systems," Neurocomputing, vol. 171, pp. 1454-1461, 2016.
[51] A. A. Abdelsalam, "Maximizing technical and economical benefits of distribution systems by optimal allocation and hourly scheduling of capacitors and distributed energy resources," Australian Journal of Electrical and Electronics Engineering, vol. 16, no. 4, pp. 207-219, 2019.

[52] J.-P. Chiou, C.-F. Chang, and C.-T. Su, "Variable scaling hybrid differential evolution for solving network reconfiguration of distribution systems," IEEE Transactions on Power Systems, vol. 20, no. 2, pp. 668-674, 2005.

[53] R. D. Zimmerman, C. E. Murillo-Sánchez, and R. J. Thomas, "MATPOWER: steady-state operations, planning, and analysis tools for power systems research and education," IEEE Transactions on Power Systems, vol. 26, no. 1, pp. 12-19, 2010.

[54] H. R. Tizhoosh, "Opposition-based learning: a new scheme for machine intelligence," in Proceedings of the International Conference on Computational Intelligence for Modelling, Control and Automation and International Conference on Intelligent Agents, Web Technologies and Internet Commerce, Vienna, Austria, November 2005.

[55] S. Rahnamayan, H. R. Tizhoosh, and M. M. A. Salama, "Opposition-based differential evolution," IEEE Transactions on Evolutionary Computation, vol. 12, no. 1, pp. 64-79, 2008.

[56] S. Rahnamayan, H. R. Tizhoosh, and M. M. A. Salama, "Opposition versus randomness in soft computing techniques," Applied Soft Computing, vol. 8, no. 2, pp. 906-918, 2008.

[57] S. Rahnamayan, H. R. Tizhoosh, and M. M. A. Salama, "Quasi oppositional differential evolution," in Proceedings of the IEEE Congress on Evolutionary Computation, Singapore, September 2007.

[58] A. A. Jain, B. J. Rabi, and S. S. Darly, "Application of QOCGWO-RFA for maximum power point tracking (MPPT) and power flow management of solar PV generation system," International Journal of Hydrogen Energy, vol. 45, no. 7, pp. 4122-4136, 2020.

[59] K. H. Truong, P. Nallagownden, I. Elamvazuthi, and D. N. Vo, "A Quasi-Oppositional-Chaotic Symbiotic Organisms Search algorithm for optimal allocation of DG in radial distribution networks," Applied Soft Computing, vol. 88, p. 106067, 2020.

[60] T. Xiang, X. Liao, and K.-w. Wong, "An improved particle swarm optimization algorithm combined with piecewise linear chaotic map," Applied Mathematics and Computation, vol. 190, no. 2, pp. 1637-1645, 2007.

[61] M. E. Baran and F. F. Wu, "Optimal capacitor placement on radial distribution systems," IEEE Transactions on Power Delivery, vol. 4, no. 1, pp. 725-734, 1989.

[62] A. Hamouda, N. Lakehal, and K. Zehar, "Heuristic method for reactive energy management in distribution feeders," Energy Conversion and Management, vol. 51, no. 3, pp. 518-523, 2010.

[63] D. Zhang, Z. Fu, and L. Zhang, "An improved TS algorithm for loss-minimum reconfiguration in large-scale distribution systems," Electric Power Systems Research, vol. 77, no. 5-6, pp. 685-694, 2007.

[64] A. Rabiee and S. M. Mohseni-Bonab, "Maximizing hosting capacity of renewable energy sources in distribution networks: a multi-objective and scenario-based approach," Energy, vol. 120, pp. 417-430, 2017.

[65] T.-L. Huang, Y.-T. Hsiao, C.-H. Chang, and J.-A. Jiang, "Optimal placement of capacitors in distribution systems using an immune multi-objective algorithm," International Journal of Electrical Power \& Energy Systems, vol. 30, no. 3, pp. 184-192, 2008. 